\title{
REDUCING PREJUDICE THROUGH SELF-AFFIRMATION
}

\begin{tabular}{c} 
A Dissertation \\
presented to \\
the Faculty of the Graduate School \\
at the University of Missouri-Columbia \\
In Partial Fulfillment \\
of the Requirements for the Degree \\
Doctor of Philosophy \\
\hline Dr. B. Ann Bettencourt, Dissertation Supervisor \\
MAY 2020 \\
MOLIE A. PRICE-BLACKSHEAR
\end{tabular}


The undersigned, appointed by the Associate Vice Chancellor of the Office of Research and Graduate Studies, have examined the dissertation entitled

\section{REDUCING PREJUDICE THROUGH SELF-AFFIRMATION}

presented by Mollie A. Price-Blackshear

a candidate for the degree of Doctor of Philosophy of Psychology, and hereby certify that, in their opinion, it is worthy of acceptance.

Professor B. Ann Bettencourt

Professor Andrea Figueroa-Caballero

Professor Jordan A. Booker

Professor Laura A. King

Professor Jamie Arndt 
.In dedication to my loving husband, Nicholas B. Blackshear, my wonderful parents and in-laws, and the most supportive friends, family, and Psychological Sciences department a person could ask for. 


\section{ACKNOWLEDGEMENTS}

I would like to thank my advisor, Dr. B. Ann Bettencourt, for her assistance with and support for this project and for all of my academic endeavors. I am grateful for the opportunity to have begun my academic career with you.

In addition, I would like to thank my other committee members, Drs. Andrea Figueroa-Caballero, Jordan A. Booker, Laura A. King, and Jamie Arndt for their generous feedback on the study designs and the written report.

I would also like to thank the Department of Psychological Sciences at the University of Missouri, Columbia for providing partial funding support for this project.

In addition, I would like to thank Kelsey Lovell for her substantial help with the development of Study 2 materials.

Finally, I would like to thank James E. Wages for the opportunity to discuss psychological science and ideas together. 


\section{TABLE OF CONTENTS}

ACKNOWLEDGEMENTS ............................................................................... ii

LIST OF ILLUSTRATIONS ........................................................................... iv

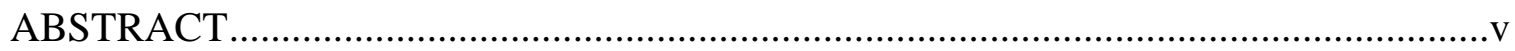

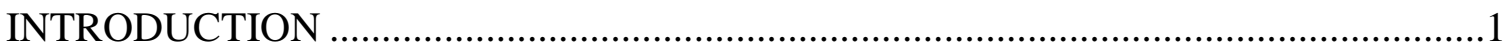

Self-Affirmation Reduces General Threat ............................................................4

Self-Affirmation and Ingroup Threats ...........................................................6

Self-Affirmation and Outgroup Threats ............................................................

Mediating Mechanisms .......................................................................... 11

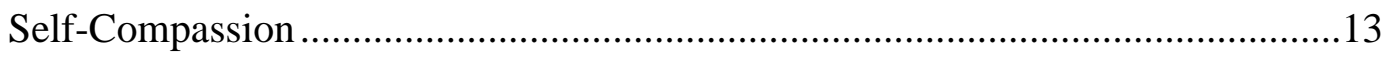

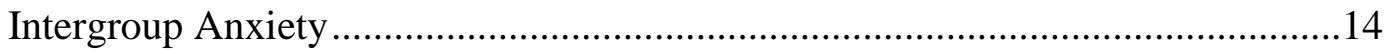

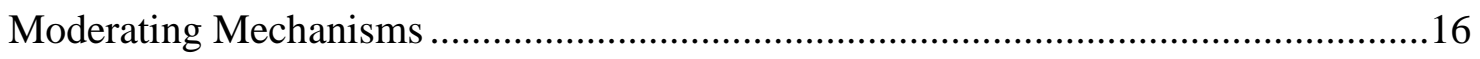

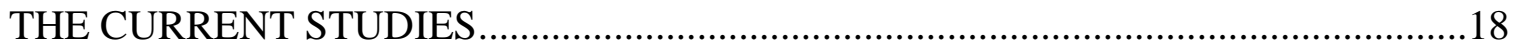

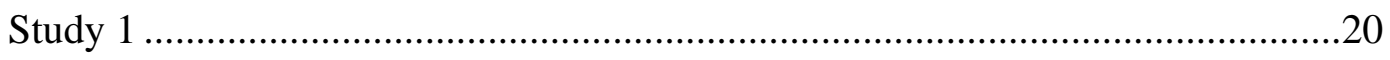

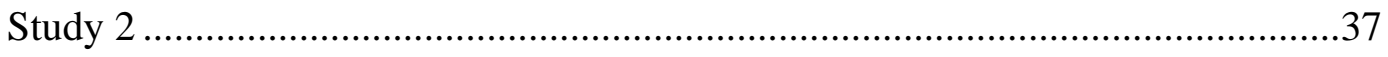

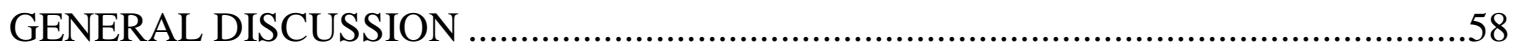

REFERENCES ........................................................

APPENDIX ............................................................. 90

1. APPENDIX A: STUDY 1 QUALTRICS ITEMS $\ldots \ldots \ldots \ldots \ldots \ldots \ldots \ldots \ldots \ldots \ldots$

2. APPENDIX B: PRETESTING FOR STUDY 2 LINKEDIN PROFILE .........103

3. APPENDIX C: STUDY 2 QUALTRICS ITEMS ......................... 104

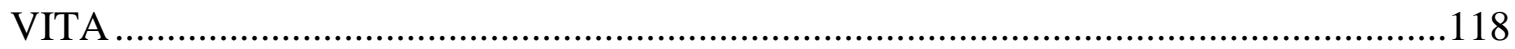




\section{LIST OF ILLUSTRATIONS}

Tables

1. Table 1: Pearson Correlations among Primary Study 1 Variables.........................84

2. Table 1: Pearson Correlations among Primary Study 2 Variables.........................85

Figures

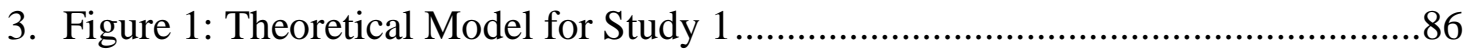

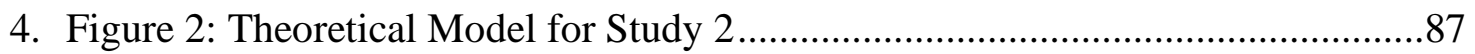

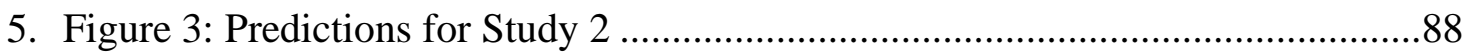

6. Figure 4: Effects for Self-Affirmation on Positive Attitudes toward African Americans, Study 2 


\begin{abstract}
Research suggests that self-affirmation can reduce threat in a multitude of domains (e.g., stereotype threat). Given the capacity for self-affirmation to reduce threats to the self of various types, the current work examined the capacity for self-affirmation to reduce outgroup prejudice. Outgroup prejudice toward groups that have traditionally been stigmatized in the U.S. (i.e., Muslims, Atheists, African Americans) were explored. Mediating mechanisms (self-compassion, intergroup anxiety) and moderating mechanisms (collective self-esteem) were also examined. In Studies 1 and 2, it was predicted that as compared to a control condition, participants that engaged in a selfaffirmation condition would show less prejudice and more positive outgroup attitudes, on measures of outgroup attitudes and job candidate evaluation ratings. In Study 2, a candidate condition had participants review either an African or White American job candidate for a job, and the interactive effects with this candidate condition and selfaffirmation were examined. Under some circumstances, self-affirmation led to higher ratings of outgroup attitudes and lower levels of prejudice. Specifically, significant and marginal main and interactive effects of self-affirmation and candidate condition were found. Including covariates led to relationships that emerged as marginal or significant for self-affirmation or its interaction with candidate conditions. Covariates (i.e., political ideology, religion, motivation to control prejudice) were also marginal or significant predictors of the majority of the outcomes. Finally, significant effects of counterbalancing influenced some of the outcomes and intergroup anxiety, and interacted with candidate on some of the outcomes. Taken together, the results of the current studies suggest that self-affirmation can indeed improve attitudes among religious and racial outgroup members in the United States. However, other demographic and individual
\end{abstract}


difference variables influenced this effect. Examining conditions to reduce prejudice are important, because understanding ways of reducing prejudice will help foster harmony between members of different social groups.

Key words: self-affirmation, prejudice, outgroup attitudes, self-compassion, intergroup anxiety 


\section{Reducing Prejudice through Self-Affirmation}

When the self feels threatened, prejudicial judgments toward outgroup members can serve as a defensive way to maintain self-integrity (Sherman \& Cohen, 2006). Outgroup members may be perceived as threatening, and one reason a person may report negative attitudes and prejudice toward outgroups is to improve their self-worth under conditions of threat. This general finding has been shown in many areas of social psychology: social identity theory (Tajfel \& Turner, 1986), system justification theory (Jost, Banaji, \& Nosek, 2004), and symbolic and realistic threats (Stephan \& Stephan, 2000), to name a few. Indeed, Fein and Spencer (1997) suggest that prejudice is a common and effective self-affirming act: when a person uses stereotypes or engages in prejudice toward outgroup members, it may serve as a way to mitigate threats to the self. Theory suggests that self-affirmation may be one strategy to reduce the tendency to engage in prejudice when threatened (Badea \& Sherman, 2019).

Self-affirmation refers to "an act that manifests one's adequacy and thus affirms one's sense of global self-integrity" (Cohen \& Sherman, 2014, pp. 337). Self-affirmation theory argues that people are motivated to maintain their sense of self-worth; selfaffirmation plays a role in protecting the self from threats to integrity because selfaffirmations broaden one's view of the self (Sherman, 2013). Specifically, selfaffirmation allows individuals to adapt thoughts and behaviors appropriately to threatening situations; by considering domains unrelated to the threatened domain, a person's self-integrity is maintained (Sherman \& Cohen, 2006). This broadened view of the self is beneficial. Specifically, affirming the self in one domain or value can buffer against subsequent domains that are threatened (Critcher \& Dunning, 2015; Sherman \& 
Hartson, 2011). Expanding the self-concept, through self-affirmation, allows individuals to reflect on threatening information with a more global perspective-a perspective that encompasses a multitude of aspects of the self. Specifically, when a person evaluates threat within one particular domain, he or she considers the threat within the context of their broader self-concept, which allows the individual to evaluate and respond to the threatening information in a less-reactive, more rational way. The overall impact of the threat is minimized when a person considers their overall, global, multifaceted selfconcept. Because a person can draw upon a variety of roles and identities to maintain their perceived integrity (Cohen \& Sherman, 2014), this expanded self-concept helps individuals to better evaluate threatening targets or information.

Research has demonstrated that self-affirmation reduces prejudice through reductions in self-threats; when a person is affirmed in an unrelated domain or value, this may replace the necessity to engage in prejudice. Prejudice often serves as a selfaffirming function; therefore, providing a means of self-affirmation through mechanisms other than prejudice (e.g., affirming values important to one's self concept) may reduce a person's reliance on prejudice to fulfil this self-protecting function (Fein \& Spencer, 1997). Some research has suggested that self-affirmation can reduce ingroup-related threats and negative outgroup perceptions and attitudes. In addition, although selfaffirmation has been shown to reduce prejudice (e.g., Badea \& Sherman, 2019; Binning, Sherman, Cohen, \& Heitland, 2010; Cohen, Sherman, Bastardi, Hsu, McGoey, \& Ross, 2007; Fein \& Spencer, 1997; Kinias \& Fennessy, 2016; Lehmiller et al., 2010; Rudman et al., 2007; Shrira \& Martin, 2005; Zârate \& Garza, 2002), little research has examined the explanatory mechanisms (i.e., mediators and moderators) of this relationship. Therefore, 
because these explanatory mechanisms are not well known in self-affirmation literature, the current work examines the capacity for self-affirmation to reduce prejudice toward outgroups, and importantly, seeks to examine potential mechanisms which may explain this effect. In the following subsections, I review prior work considering the effects of self-affirmation on prejudice, and what little is known about mediators and moderators of the effect of self-affirmation on outgroup prejudice. 


\section{Self-Affirmation Reduces General Threat}

Self-affirmation allows people to consider information that contradicts their personal views and allows psychological resources to be maintained and enhanced (Sherman \& Cohen, 2002; Sherman, 2013). Self-affirmation has been shown to reduce the impact of threatening information in several domains; for example, it has been shown to reduce stereotype threat in academic performance, unhealthy behaviors and intentions, susceptibility to misinformation, and closed-mindedness and defensiveness (e.g., Cohen et al., 2007; Peterson et al., 2012; Sherman \& Cohen, 2002; Sherman, 2013; Sherman \& Hartson, 2011; Sherman, Hartson, Binning, et al., 2013; Stone et al., 2011; Szpitalak \& Polczyk, 2015). For example, Sherman, Hartson, Binning, et al. (2013) found that, compared to Latino American middle school students in a control condition, those in a self-affirmation condition showed reductions in an academic (i.e., stereotype threatened) domain. Specifically, those in the self-affirmation condition reported higher GPAs and sustained higher grades across three years, as compared to those in the control condition. Also, Peterson et al. (2012) implemented an intervention that combined self-affirmation with components designed to enhance positive affect, to determine whether this combined intervention would improve levels of physical activity for patients that underwent a percutaneous coronary intervention. This population of patients typically fail to engage in physical activity, though they are encouraged to do so because of the significant decreases in mortality rate that are associated with physical activity. The researchers found that the combined self-affirmation and positive affect intervention led to increases in self-reports of physical activity among these patients, compared to patients in a control condition. This suggests that as a result of self-affirmation, these patients 
were more willing to consider information that was uncomfortable and difficult given their current situation.

Given a range of evidence suggesting that self-affirmation can reduce threat across general domains, it seems plausible that self-affirmation could reduce outgroup prejudice, because prejudice can be a response to threats from the ingroup. Outgroup prejudice may manifest because outgroups are perceived as threatening to the ingroups' values or resources (i.e., symbolic or realistic threats; Stephan \& Stephan, 2000). Given that self-affirmation reduces threat in general domains, self-affirmed individuals may report less prejudice toward outgroups (i.e., threats within an intergroup domain). Indeed, prior evidence suggests that self-affirmation can reduce prejudice (for a review, see Badea \& Sherman, $2019^{1}$ ), and this evidence is reviewed below. Also, Crocker et al. (2008) suggest that social connectedness with others may be enhanced as a result of selfaffirmation, further suggesting the importance of self-affirmation within not only personal, but also social, contexts.

\footnotetext{
${ }^{1}$ Badea and Sherman (2019) provide evidence that group- and self-affirmation has been compared as means of improving outgroup attitudes. Group-affirmation involves affirming group-important values, rather than values important to the self. Research is mixed on the extent to which group-affirmations effectively reduce ingroup threats and outgroup prejudice (Badea et al., 2020; Badea \& Sherman, 2019). Research has shown that compared to control conditions, group-affirmation may diminish (e.g., Gunn \& Wilson, 2011), exacerbate (e.g., Ehrlich \& Gramzow, 2015), or have no effect (e.g., Cehajić-Clancy et al., 2011) on ingroup threats and outgroup prejudice. Research has also compared the effects of self- and groupaffirmations within the same study (e.g., Badea et al., 2017; Badea et al., 2020; Villicana et al., 2018; White et al., 2014), with mixed results. Group affirmations are not the focus of this dissertation, and will therefore not be explored in Studies 1 \& 2.
} 


\section{Self-Affirmation and Ingroup Threats}

Some evidence suggests that self-affirmation can reduce the perception of perceived threats toward the ingroup (e.g., Adams et al., 2006; Badea \& Sherman, 2019; Cehajić-Clancy et al., 2011; Davis, Soref, Villalobos, \& Mikulincer, 2016; Hideg \& Ferris, 2014; Hoorens, Dekkers, \& Deschrijver, 2020; Lowery et al., 2007; Uhlmann \& Nosek, 2012; see also Kahn et al., 2016). For example, Adams et al. (2006) found that, compared to those in a control condition, White Americans in a self-affirmation condition were more likely to acknowledge reports of racism in the U.S. and were more likely to support the belief that their group generally denies racism. Furthermore, the researchers found that White Americans' acknowledgement of racism following a self-affirmation condition were more similar to Latinos' reports of racism, suggesting that self-affirmation can reduce group discrepancies in reports of racism directed toward stigmatized outgroups. Relatedly, Lowery et al. (2007) found that White Americans in a selfaffirmation condition perceived more White privilege and provided more support for redistributive hiring policies, compared to control participants. Also, Cehajić-Clancy et al. (2011) found that Serbian participants were more willing to express ingroup-based guilt and responsibility for Srebrenica genocide under self-affirmation condition as compared to a control condition. These results suggest that self-affirmation can reduce ingroup threats (e.g., acknowledgement of ingroup wrongdoing; outgroup disadvantage). Given that self-affirmation can be used as a strategy to mitigate the effects of threat, this research suggests that within an intergroup context, self-affirmation can reduce defensiveness toward information that presents the ingroup within a negative light. 


\section{Self-Affirmation and Outgroup Threats}

Evidence also suggests that self-affirmation can be influential in reducing outgroup prejudice toward many types of outgroups (e.g., Badea \& Sherman, 2019; Binning, Sherman, Cohen, \& Heitland, 2010; Cohen, Sherman, Bastardi, Hsu, McGoey, \& Ross, 2007; Fein \& Spencer, 1997; Kinias \& Fennessy, 2016; Lehmiller et al., 2010; Rudman et al., 2007; Shrira \& Martin, 2005; Zârate \& Garza, 2002; but see Vance, 1998). Prior research examining the effects of self-affirmation on outgroup attitudes has focused on using manipulations of self-affirmation in which participants write about values important to the self — a method that is among the most widely used (McQueen \& Klein, 2006). Furthermore, these self-affirmation studies have primarily focused on political and racial/ethnic outgroups. With regard to political outgroups, Binning et al. (2010) recruited Democrats and Republicans for a study designed to examine selfaffirmation and political attitudes. The researchers manipulated self-affirmation by first asking participants to rank-order ten non-political values from most to least important to themselves personally, and then participants were asked to write about either the value most important to them (self-affirmation condition) or the value least important to them (control condition). Next, participants were shown clips from a 2008 presidential debate between Obama (Democratic candidate) and McCain (Republican candidate). Finally, participants were asked to rate (for each candidate) the favorability of the debateperformance. The results showed that self-affirmation reduced partisanship: Republicans showed significantly greater favorability toward Obama (and Democrats showed marginally less favorability), as compared to control participants. In addition, in a short- 
term follow-up, Republicans in the self-affirmation condition indicated a significantly more positive outlook on Obama's presidency than non-affirmed Republicans.

Cohen et al. (2007, Study 2) examined the influence of self-affirmation on partisan closed-mindedness. Pro-choice participants were brought into the lab to engage in a negotiation task with a confederate purported to be of a pro-life inclination. The participants' and confederate's ostensible goal was to reach consensus on legislation providing provisions for abortion restrictions. Before the negotiation, participants engaged in a typical self-affirmation condition (i.e., writing about their most important value) or wrote about a time in which they hurt, or failed to help, another person (threat condition). The researchers also gave half of the participants the ability to indicate which aspects of the bill they would remove or retain prior to the negotiations taking place (i.e., convictions salient condition). The researchers found that under the convictions salient condition, self-affirmation participants made significantly greater concessions on the bill to the pro-life confederate, and rated this confederate significantly more favorably, than those in the threatening condition.

As mentioned previously, racial and ethnic outgroups have also been examined in prior self-affirmation research (e.g., Fein \& Spencer, 1997; Kinias \& Fennessy, 2016; Rudman et al., 2007; Shrira \& Martin, 2005; Zârate \& Garza, 2002). Fein and Spencer (1997) were interested in the effects of self-affirmation on rating an outgroup job candidate. U.S. undergraduate participants reviewed application materials and a videotaped interview of a candidate that was either presumed Jewish (a highly stigmatized outgroup) or presumed Italian (a non-stigmatized outgroup). The researchers found that job candidates were rated more negatively (e.g., more negative trait ratings and 
lower job qualifications) when portrayed as Jewish than portrayed as Italian. However, the researchers found that this effect was eliminated for participants who had engaged in a self-affirmation condition: these participants rated Jewish and Italian job candidates equivalently on trait and job qualification ratings. These findings suggest that prejudice (i.e., rating ingroup and outgroup job candidates of equivalent status differently) can be reduced as a result of self-affirmation.

Zârate and Garza (2002) examined whether a combination of ingroup distinctiveness and self-affirmation would reduce prejudice toward ethnic outgroup members. A mixed-race sample of participants (e.g., Mexican, White, African, and Asian Americans, and Mexican Nationals), was randomly assigned to rate either how similar to or how different their ethnic ingroup and outgroup were on a series of traits. Then, participants were randomly assigned to a self-affirmation or control condition. The researchers found that the combination of making difference-comparisons coupled with self-affirmation led to participants reporting lower levels of prejudice, as compared to difference-comparison individuals in the control condition. The similarity condition showed equal outgroup ratings in the self-affirmation and control conditions. These studies suggest that prejudice (operationalized as attitudes toward outgroups) may be lower under conditions of self-affirmation.

Kinias and Fennessy (2016) compared the effectiveness of using a selfaffirmation condition for reducing prejudice to three other conditions: a brief mindfulness meditation, an authentic best-self writing reflection, and a control writing condition. Prejudice was operationalized as the extent to which participants reported that prejudice, discrimination, and racism played a part in ten policies or events in the U.S. (e.g., 
removing the Confederate flag from government buildings). The researchers further examined the mediating role of eudaimonic well-being among these relationships. The researchers found that among an adult Amazon Mechanical Turk sample, participants in the self-affirmation and the authentic best self-reflection conditions indicated significant reductions in prejudice through eudaimonic well-being; the control and mindfulness conditions did not lead to lower levels of prejudice. These results provide evidence that willingness to consider or recognize reports of racism may be enhanced following selfaffirmation. Importantly, the results also suggest the importance of considering explanatory mechanisms (i.e., mediators) of the relationship between self-affirmation and prejudice (e.g., eudaimonic well-being).

Shrira and Martin (2005) examined the effects of self-affirmation and cerebral hemisphere activation on stereotyping toward a non-stigmatized (female librarian) and a stigmatized (Arabic man) outgroup. The researchers found that those in the selfaffirmation condition reported lower levels of stereotyping toward the Arabic man and showed higher levels of stereotyping toward the librarian, as compared to a control condition. This work suggests that self-affirmation may be most effective at improving prejudice when considering targets from outgroups that are highly stigmatized, and therefore, more threatening. Indeed, the work of Shrira and Martin (2005), as well as Fein and Spencer (1997) conclude that self-affirmation may be most effective at reducing prejudice when target outgroups are particularly stigmatized (see also Adams et al., 2006). With non-stigmatized outgroups, prejudice and stereotyping may be unchanged (Fein \& Spencer, 1997) or increased (Shrira \& Martin, 2005) under conditions of selfaffirmation. 


\section{Mediating Mechanisms}

As mentioned previously, the effects of self-affirmation on outgroup prejudice are likely explained by relevant cognitive and affective processes. Few studies have examined mediators for the effect of self-affirmation on prejudice. One prior study revealed that the effect of self-affirmation on outgroup prejudice was mediated by eudaimonic well-being (Kinias \& Fennessy, 2016). ${ }^{2}$ Also, Badea et al. (2018) found that self-affirmation reduced support for discriminatory policies toward immigrants, and found that perceptions of symbolic and realistic threats were mediators of this effect. Self-affirmation led to lower perceptions of symbolic and realistic threats, and lower levels of these threats (as two separate mediators) were associated with lower support for discriminatory policies toward immigrants. Also, several studies have failed to find that changes in mood are an explanatory mechanism: research shows that the relationship between self-affirmation and prejudice is not mediated by changes in mood or affect (e.g., Fein \& Spencer, 1997; Shrira \& Martin, 2005; see also Schneider, 2018).

The effects of additional mediating mechanisms (e.g., self-compassion, intergroup anxiety) are discussed, as I hypothesized that these variables may mediate the relationship between self-affirmation and prejudice. Self-compassion involves an openness to one's suffering and failures, and a desire to heal the self with kindness (Neff, 2003). One reason that self-affirmation may reduce prejudice is because self-affirmation may lead to higher levels of self-compassion, which in turn, may lead to lower levels of perceptions of criticism and vulnerability to threat. Given that self-compassion and

\footnotetext{
${ }^{2}$ In addition, Shrira \& Martin (2005) found that a line bisection task mediated the relationship between selfaffirmation and increased prejudice toward a non-stigmatized outgroup (librarian), but did not mediate the relationship between self-affirmation and decreased prejudice toward a stigmatized outgroup (Arabic man).
} 
positive self-regard lead to higher levels of prosocial behavior, it is of interest to examine if these positive downstream consequences would extend to outgroup prejudice. Furthermore, intergroup anxiety involves perceptions of nervousness at the prospect of interacting with members of an outgroup (Stephan \& Stephan, 1985). Given how strongly intergroup anxiety influences outgroup attitudes (Stephan, 2014), it is important to consider the effects of anxiety when considering the relationship between self-affirmation and outgroup attitudes. That is, self-affirmation should lead to lower levels of intergroup anxiety, and lower levels of intergroup anxiety should lead to lower levels of prejudice. 


\section{Self-Compassion}

Prior research has suggested that self-compassion can have an influence on attitudes toward and relationships with others. For example, Zhang et al. (2020) found that undergraduates in a romantic relationship who reported higher levels of selfcompassion showed a greater acceptance of their partners' flaws; this relationship was mediated by acceptance of the participants' own flaws. Some research has also examined self-compassion as a mechanism that influences self-affirmation (Lindsay \& Creswell, 2014). For example, Lindsay and Creswell found that a self-affirmation manipulation led to increases in prosocial behavior (e.g., donations to charities; willingness to help after a shelf-collapse incident). In addition, they speculated that self-affirmation would lead to increases in self-compassion because self-affirmation has been associated with increases in feelings of social connection (Crocker et al., 2008). Lindsay and Creswell found that self-compassion mediated the relationship between self-affirmation and prosocial behavior; self-affirmation led to increases in levels of self-compassion, which led to increases in helping behavior, and the mediational path was significant. Schneider (2018) extends this work by showing that the effect of self-affirmation increasing prosocial behavior can also be mediated by positive self-regard. The findings of Lindsay and Creswell (2014) and Schneider (2018) suggest that an important explanatory mechanism for the self-affirmation effect involves self-directed positive feelings, which can have further positive downstream consequences for others. Given the capacity for selfcompassion to show mediating influences on self-affirmation, it is of interest to examine whether the influences of self-affirmation on outgroup prejudice are partially explained by self-compassion. 


\section{Intergroup Anxiety}

Intergroup anxiety is characterized by a general sense of fear that something negative or bad may happen if a person interacts with members of an outgroup, such as disapproval and embarrassment (Stephan \& Stephan, 1985). Theory and research suggest that intergroup anxiety is strongly associated with prejudice and negative outgroup attitudes (Islam \& Hewstone, 1993; Stephan, 2014; Stephan et al., 2002). Specifically, if people indicate they are more nervous at the prospect of interacting with outgroup members, then they are likely to indicate more negative attitudes and higher levels of prejudice toward those outgroups, as compared to individuals that are low in intergroup anxiety. Some research suggests that variables similar to but conceptually distinct from intergroup anxiety, symbolic and realistic threats, can mediate the relationship between self-affirmation and support for discriminatory policies (Badea et al., 2018). Symbolic threats are those that involve perceptions that the outgroup differs from the ingroup in terms of standards, values, attitudes, and beliefs; realistic threats are those that involve ingroup security, welfare, and economic and political power in comparison to the outgroup (Badea et al., 2018). Although research suggests that symbolic and realistic threats can serve as a mediator of the relationship between self-affirmation and support for discriminatory policies (Badea et al., 2018), and though there may be conceptual overlap between symbolic and realistic threats and intergroup anxiety, no prior research has examined the relationship between self-affirmation and intergroup anxiety. The current work differs from Badea et al. (2018) in an important way. Namely, Badea et al. (2018) examined whether realistic and symbolic threats mediate the relationship between self-affirmation and support for discriminatory policies. The current work examined 
whether intergroup anxiety mediated the relationship between self-affirmation and outgroup attitudes. Intergroup anxiety is a mediator more congruent with examining outgroup attitudes, as compared to realistic and symbolic threats. That is, intergroup anxiety (perceptions of nervousness toward interacting with outgroup members) is likely a better explanatory mechanism for the relationship between self-affirmation and prejudice, as compared to perceptions that the outgroup is a symbolic or realistic threat to the ingroup. Therefore, the mediating influences of intergroup anxiety were examined in Studies 1 and 2. 


\section{Moderating Mechanisms}

Prior research has examined whether the relationship between self-affirmation and prejudice is moderated by other variables, including group-related variables. Badea et al. (2018) found that individualism moderated the relationship between self-affirmation and support for discriminatory policies toward immigrants. The researchers examined the interaction between individualism (low vs. high) and their experimental conditions (selfaffirmation vs. group- affirmation vs. control). As compared to a group-affirmation and control condition, participants in a self-affirmation condition expressed lower levels of support for discriminatory policies if they reported higher levels of individualism (lower levels of individualism, in contrast, were associated with equivalent levels of policy support across the three experimental groups).

Social identity theory (Ellemers \& Haslam, 2012; Tajfel, 1982; Tajfel \& Turner, 1986) suggests that group memberships and group identity contribute meaningfully to an individual's self-concept. Indeed, groups serve an important psychological function and provide enrichment in various ways: group memberships contribute to the sense of self, fostering a sense of support and security, and improve psychological well-being and selfesteem, among other benefits. Although Adams et al. (2006) did not examine moderators of the self-affirmation effect in their research, they suggest the importance of testing group identification as a potential moderator ${ }^{3}$ of the relationship between self-affirmation and prejudice (pp. 624), though they do not specify a predicted pattern of results. Sherman et al. (2007) found that group identification with a sports team moderated the relationship between affirmation paradigm (self vs. group vs. control) and attributions

\footnotetext{
${ }^{3}$ Or mediator (Adams et al., 2006, pp. 624).
} 
participants made following team wins and losses (Study 2). Cohen et al. (2007) found that identity salience moderated the association between self-affirmation and willingness to consider pro-life policies among pro-choice participants. The researchers found that self-affirmation showed the strongest effects for participants who were presented with questionnaire items that dealt with importance for standing up for values (convictions salient condition) as compared to those presented with items dealing with the importance of being rational (rationality salient condition).

Badea and Sherman (2019) ${ }^{4}$ suggest that group identification can moderate the relationship between affirmation paradigms (i.e., self-affirmation, group-affirmation) and outgroup attitudes. The authors focus on group identification as a moderator for group affirmation primarily, though it could be argued that group identification may play a moderating role for self-affirmation as well (but see Sherman et al., 2007). Given the potential for group identification to influence prejudice, it was explored as a moderator of the relationship between self-affirmation and prejudice in Study 2.

\footnotetext{
${ }^{4}$ Another potential moderator (cultural norms) have been speculated to be a moderator of the relationship between affirmation paradigms and prejudice (Badea \& Sherman, 2019). Smeekes and Verkuyten (2014) suggest that the cultural norms surrounding intergroup attitudes can influence prejudice and outgroup attitudes. Badea and Sherman (2019) use the rationale of Smeekes and Verkuyten (2014) to suggest that the cultural norms and social context surrounding different groups may have an impact on the capacity for group-affirmation (in particular) to reduce prejudice and improve attitudes (i.e., cultural norms and social context may serve as a moderator of the relationship between group-affirmations and prejudice). Specifically, Badea and Sherman (2019) suggest that cultural norms of tolerance may lead to group affirmations leading to reductions in prejudice; however, cultural norms of intolerance may lead to group affirmations increasing prejudicial attitudes.
} 


\section{The Current Studies}

Given the negative consequences of prejudice, it is important to examine the conditions in which prejudice may be mitigated; self-affirmation may provide one such way to reduce prejudice. Self-affirmation expands the working self-concept and provides individuals the ability to view themselves in a multifaceted framework. Self-affirmation has been shown to reduce threats to the self in a multitude of domains; by allowing an individual to become affirmed in domains unrelated to a threat, they become less influenced by information typically threatening to the self. Given its capacity to reduce threat in general domains, additional findings suggest that self-affirmation has the capacity to reduce outgroup prejudice. If prejudice serves as a self-affirming mechanism, then providing an opportunity for self-affirmation using another strategy (e.g., writing about values important to the self) should reduce reliance on prejudice as a selfprotecting mechanism. Given this expanded self-concept, it is expected that individuals would report lower levels of prejudice toward outgroup members. Specifically, it is hypothesized that participants engaged in self-affirmation would report lower levels of outgroup prejudice as compared to a control condition (Hypothesis I). These relationships were examined on Amazon Mechanical Turk, across two studies with White Americans, which examined attitudes toward two stigmatized outgroups (Muslims, African Americans) and using different measures to examine outgroup prejudice (feeling thermometers, positive and negative attitudes, and job candidate evaluation ratings).

Examining what mechanisms may reduce defensiveness toward outgroups may be imperative, given that prior self-affirmation and prejudice research has had a limited focus on explanatory mechanisms. It was expected that the effects of self-affirmation on 
outgroup prejudice may be mediated by affect-related mechanisms. First, it was hypothesized that intergroup anxiety would mediate the relationship between selfaffirmation and prejudice: self-affirmation would have a negative effect on intergroup anxiety, and intergroup anxiety would in turn positively predict outgroup prejudice (Hypothesis II). It was also expected that self-compassion would mediate the effect of self-affirmation on prejudice. Specifically, it was expected that self-affirmation would positively predict self-compassion, which would in turn lead to lower levels of outgroup prejudice (Hypothesis III). In Study 2, a moderated-mediational analysis was proposed to examine whether there was a moderating role of group identification among these relationships. Specifically, it was expected that group identification would moderate the relationship between self-affirmation and intergroup anxiety, such that those with higher levels of group identification would report higher levels of intergroup anxiety, as compared to those with lower levels of group identification (Hypothesis IV). Also, it was expected that group identification would moderate the relationship between selfaffirmation and outgroup prejudice; such that those that were more strongly identified with the ingroup would report higher levels of outgroup prejudice, as compared to those weakly identified with the ingroup (Hypothesis V). Figures 1 and 2 provide proposed theoretical mediational models for Studies 1 and 2, respectively. 


\section{Study 1}

Study 1 was designed as an initial test of the theoretical model depicted in Figure 1. Given that prior research suggests that self-affirmation leads to lower levels of prejudice particularly for stigmatized outgroups (Adams et al., 2006; Fein and Spencer, 1997; Shrira \& Martin, 2005), Study 1 examined the effects of self-affirmation using Muslims as the target outgroup. Muslims are a social group that are highly stigmatized in the U.S., and this stigmatization has continued in the current political climate (Abu-Ras et al., 2018; Casey, 2017). U.S. participants from Amazon Mechanical Turk (MTurk) were recruited for Study 1, given that prior meta-analytic evidence suggests that effects for self-affirmation studies are stronger among non-student samples as compared to student samples (Forscher et al., 2019). Only White, non-Muslim participants were included in data analyses, because outgroup attitudes toward Muslims were of interest in this work. Furthermore, Muslims are often stigmatized as deviating from a White, Christian mainstream (Casey, 2017), and White Americans are therefore more likely to perceive Muslims as threatening. Explicit measures of prejudice were of interest in this work, given prior meta-analytic evidence which suggests that self-affirmation procedures have stronger effects on explicit, as compared to implicit, measures of prejudice (Forscher et al., 2019). It was expected that those in the self-affirmation condition would report lower levels of prejudice toward Muslims (higher ratings on feeling thermometers and positive attitudes, and lower negative attitudes) as compared to those in the control condition. It was further expected that self-compassion and intergroup anxiety would mediate these relationships.

\section{Method}




\section{Participants}

Participants were recruited via MTurk. Originally, $N=453$ MTurk workers participated in this study. Participants were removed from the dataset if they answered zero of three attention checks correctly $(N=2)$, if they identified as an ethnicity other than White $(N=10)$, if they identified as Muslim $(N=1),{ }^{5}$ or if they answered a manipulation check incorrectly $(N=31)$. The resulting $N$ was 409 White American participants. A power analysis determined that a sample size of $N=328$ participants would be needed to obtain a power of .95 to detect a small effect of .20 , to examine differences between two groups. There were no duplicate IP addresses in the dataset. The majority of the sample identified as female $(N=263$; male $N=144$; other $N=2)$. The mean age of the sample was 43.72 years $(S D=14.54$, range of 18 to 82 years). Political ideology was measured on a 1 (strongly conservative) to 7 (strongly liberal) scale $(M=$ $4.35, S D=1.84)$; in the sample, participants identified as very conservative, conservative, or slightly conservative $(N=135)$, moderate $(N=85)$, or slightly liberal, liberal, or very liberal $(N=189)$. Participants identified as Christian-Protestant $(N=233)$, ChristianCatholic $(N=76)$, Mormon $(N=5)$, Jewish $(N=10)$, Buddhist $(N=6)$, Atheist $(N=83)$, or selected "Other please specify" $(N=92)$. A new religion variable $(0=$ Christian, $1=$ Non-Christian) was coded as follows: Christian-Protestant, Christian-Catholic, Mormon, and "Other" responses which reported a Christian-related affiliation (e.g., Baptist, Unitarian, Christian Spiritual) were recoded as Christians $(N=238)$; Jewish, Buddhist, Atheist, and "Other" responses which reported a non-Christian-related category (e.g., Agnostic, Spiritual, Not Religious) were recoded as Non-Christians $(N=171)$.

\footnotetext{
${ }^{5}$ Because of the interest in outgroup attitudes, Muslim adults were ineligible for participation.
} 
Participants were provided with a link to a Qualtrics study. Participants were compensated with $\$ 0.50$ for their participation in this online experiment. Participants were told the following in the consent form: "In this study, you will be asked to write about values important to yourself and/or others. After this, you will answer some questions about your experiences and opinions. The study is designed to understand the ways in which values are related to your perspectives about the United States and other people." Study 1 methods and predicted results were preregistered on Open Science Framework (https://osf.io/nh78y); deviations from the preregistration (i.e., "exploratory analyses") are specified below.

\section{Procedure}

The study used a between-subjects design. Participants were randomly assigned to either a self-affirmation or control condition. Following the same procedure adopted in other studies (e.g., Badea, Bender, \& Korda, 2020), all participants were given a list of values (listed below) and rank-ordered the values from most to least importance to them. Those in the self-affirmation condition wrote about the value they identified as most important; those in the control condition wrote about the value least important to them. Data quality was considered by the author, who screened the participants' responses to the manipulation, to ensure participants wrote about the topic they were expected to write about, and to ensure the manipulation directions were followed. Other means of assessing data quality (e.g., time writing and word count) are discussed below. Upon completion of the manipulation, participants were asked to answer questions measuring the mediating variables (intergroup anxiety and self-compassion), and participants were assessed for attitudes toward Muslims (see the Counterbalancing Procedure section below for 
clarification on the presentation of measures and the manipulation). Upon completion of the study, participants were debriefed, thanked, and compensated online.

In self-affirmation research, although the majority of self-affirmation studies have failed to specify time or word length requirements for writing, a few researchers have specified the allotted time participants were given to write (e.g., 10 to 15 minutes; Cohen et al., 2007), and others have specified a required number of words or sentences, such as one to two sentences (Binning et al., 2010) or 130 to 140 words (Davis, Soref, Villalobos, \& Mikulincer, 2016). Other researchers did not restrict word length ahead of time, but have considered word length post-hoc and found no differences between self-affirmation and control conditions in length of responses (Creswell et al., 2013). Participants in the current study were not restricted with respect to time writing or word count; however, time spent on the writing task was timed via Qualtrics, and word count of writing responses was determined via Excel and entered into the SPSS dataset; these factors were examined post-hoc. Specifically, differences between conditions on time writing and word count were tested and presented in the results section, and these variables were included as covariates in further analyses. Furthermore, few researchers consider the values that participants choose to write about, and whether those values differ by condition (but see Creswell et al., 2013; Lehmiller et al., 2010; Sherman et al., 2007); the most frequently chosen value and its impact on participants given the current historical context (i.e., COVID-19) are discussed in the general discussion section.

Regarding control conditions, some research involved participants recalling everything they ate and drank within the past 48 hours (Cohen, et al., 2000; De Roos, 2018), list all uses of a knife (Harvey \& Oswald, 2000), list mundane tasks (Schimel, 
Arndt, Banko, \& Cook, 2004) or write about a time in which they failed to achieve their highest-ranked value (Cohen et al., 2007). In most studies, however, participants write about their lowest-ranked value. Given the consistent use of this procedure in prior literature (McQueen \& Klein, 2006), participants in the control condition of the current study wrote about the value they ranked as least important to them.

\section{Manipulation}

Self-affirmation domains. Participants were provided with eleven values and domains used in prior literature (Creswell et al., 2013; Sherman, Bunyan, Creswell, \& Jaremka, 2009) and asked to rank the domains from most to least importance to them. The domains that were used are artistic skill, athletics, business/money, creativity, independence, music, relationships, religious values, sense of humor, politics, and spontaneity. ${ }^{6}$ After ranking the domains from most to least important, those in the selfaffirmation condition were asked to write about the value they selected as the most important to them, explaining why they ranked it as the most important, and describing a time in their lives in which the value was meaningful. A relevant meta-analysis reviewing experimental manipulations of self-affirmation (McQueen \& Klein, 2006) specifies that this procedure is among the most widely used method to manipulate self-affirmation;

\footnotetext{
${ }^{6}$ These are not the only values used in self-affirmation research. The following lists of values have been used previously — some of these lists have been inspired by Allport, Vernon, \& Lindzay (1960) and/or Harber (1995). Many lists have overlapping concepts among the items represented. List 1) artistic skills, sense of humor, relationship with friends/family, spontaneity, creativity, athletics, musical ability, business/managerial skills, physical attractiveness, romantic values, social skills (Cohen et al., 2000; De Roos, 2018). List 2) art/music/theater, social life/relationships, business/economics/making money, religion/spirituality, social action/helping others, science/pursuit of knowledge (Shrira \& Martin, 2005). List 3) honesty, loyalty, respect, family, empathy, listening, tolerance, love, sharing (Badea et al., 2020). List 4) honesty, loyalty, family, friendships, creativity, athletics, business/money, religion/spirituality, social issues, concern for others, independence, politics, self-discipline, self-respect, originality, patience, appearance/fashion, social skills (Gunn \& Wilson, 2011). List 5) artist, comedian/funny person, athlete, musician, entrepreneur, student, nurse, doctor, lawyer, mathematician, scientist, engineer (Schimel et al., 2004).
} 
therefore, this widely used procedure was used in this work. Those in the control condition, in contrast, were asked to write about the value least important to them, explaining why the value was least important to them, and describe an instance in which the value would be meaningful to another person. The self-affirmation manipulation and other measures for Study 1 are included in Appendix A.

\section{Measures}

Outgroup attitudes. Participants were asked to provide their attitudes toward Muslims. Following Amiot and Hornsey (2010), participants were first given feeling thermometers (i.e., 0 to 100), and asked to indicate the amount of each of four thermometers (i.e., cold/warm, unfriendly/friendly, distant/close, different/similar) they felt toward Muslims; these four items were combined to form an index of feeling thermometers toward Muslims, $\alpha=.90$. Then, participants were provided with a series of adjectives (i.e., intelligent, friendly, likeable, immature, cultivated, boring, talented, sympathetic, stubborn, trustworthy, bad, dishonest, truthful) and asked to indicate how they believed Muslims ranked on each adjective (i.e., $1=$ not at all; $9=$ extremely). The eight positive attitudes $(\alpha=.95)$ and the five negative attitudes $(\alpha=.84)$ were explored as separate positive and negative attitude outcomes.

To mask the interest in collecting responses toward Muslims, participants were provided with feeling thermometer ratings toward 4 other religious categories (Christians, Hindus, Buddhists, \& Atheists). Participants also rated Christians and Atheists on the positive and negative adjectives (attitudes) ratings. Exploratory analyses examined the feeling thermometers $(\alpha=.90)$, positive attitudes $(\alpha=.93)$, and negative attitudes $(\alpha=$ .83) toward Atheists. 
Intergroup anxiety. The Intergroup Anxiety scale (Stephan \& Stephan, 1985) measured negative emotions toward interacting with a group of Muslims (i.e., $0=$ not at all, $9=$ extremely). Participants were asked to indicate the extent to which they felt each of six negative items (e.g., uncertain, worried, awkward, anxious, threatened, and nervous) and six positive items (e.g., comfortable, trusting, friendly, confident, safe, and at ease). Positive items were reverse-coded, and items were combined to form a measure of intergroup anxiety, $\alpha=.96$.

Self-compassion. Self-compassion was measured using the 12-item SelfCompassion Scale-Short Form (Raes, Pommier, Neff, \& Van Gucht, 2011). An example item includes: "I try to see my failings as part of the human condition" and the scale was measured using a 5-point Likert scale $(1=$ Almost never, $5=$ Almost always, $\alpha=.89)$.

\section{Statistical Analyses}

First, in a regression analysis, self-affirmation condition $(1=$ self-affirmation; $0=$ control) was examined as a predictor of outgroup prejudice (i.e., feeling thermometers, positive attitudes, and negative attitudes). Next, if self-affirmation condition had a significant effect on the outcomes and mediators, to test the theoretical model depicted in Figure 1, the PROCESS macro (Version 3; Hayes, 2013) would be used to determine the parallel mediational influences of intergroup anxiety and self-compassion on outgroup prejudice. Finally, if self-affirmation was unrelated to the outcomes and unrelated to the mediators, covariates including political ideology $(1=$ strongly conservative $; 7=$ strongly liberal) and religion $(0=$ Christian, $1=$ Non-Christian $)$ were explored for their influences on these relationships. For example, it could be speculated that religiosity (identifying as a member of a certain religion, or no religion) may influence prejudice ratings toward 
Muslims (a religious group). Table 1 shows the zero-order correlations among the primary study variables in Study 1.

\section{Counterbalancing Procedure}

The measures were counterbalanced in Study 1, and the presentation of the manipulation and measures to participants were as follows. First, all participants engaged in the self-affirmation or control (between-subjects) writing manipulation. Half of the participants were then presented with the mediators, followed by the prejudice-related outcome measures. The other half of participants were presented with the prejudicerelated outcome measures, and this was followed by the mediators. The demographic variables (including political ideology and religion) were measured at the end of the study. The order of mediators was also counterbalanced: for the mediators, intergroup anxiety was measured prior to self-compassion for half of the sample; for the other half, self-compassion was measured prior to intergroup anxiety. The order of the outcomes were: feeling thermometers first, and then positive and negative attitudes were presented mixed together. An order variable $(1=$ mediators tested prior to outcomes, $0=$ outcomes tested prior to mediators) would be explored if there were significant effects of counterbalancing on the outcomes. In other words, it was explored whether mediators tested first (vs. outcomes tested first) had an effect on the study results. This counterbalancing procedure led to one of eight possible combinations of measures: or, a counterbalancing procedure of self-affirmation (self-affirmation vs. control) $\times$ mediator presented first (intergroup anxiety first vs. self-compassion first) $\times$ order (mediators first vs. outcomes first).

\section{Results and Discussion}




\section{Simple Regression with Self-Affirmation}

When examining the effects of self-affirmation condition $(1$ = self-affirmation, 0 $=$ control), in an ANOVA analysis, self-affirmation had no effect on positive attitudes, $p$ $=.210$, negative attitudes, $p=.295$, or feeling thermometers, $p=.109$. Specifically, Hypothesis I was not supported; those in the self-affirmation condition reported similar levels of positive attitudes $(M=5.55, S E=.11)$, negative attitudes $(M=4.32, S E=.11)$, and feeling thermometers $(M=51.06, S E=1.77)$ when compared to the control condition (positive $M=5.35, S E=.11$, negative $M=4.48, S E=.11$, feeling thermometers $M=$ $46.88, S E=1.91)$. This lack of an effect of self-affirmation condition predicting the outcomes was surprising, given prior literature which has suggested that self-affirmation can lead to lower levels of prejudice (Badea \& Sherman, 2019; Binning, Sherman, Cohen, \& Heitland, 2010; Cohen, Sherman, Bastardi, Hsu, McGoey, \& Ross, 2007; Fein \& Spencer, 1997; Kinias \& Fennessy, 2016; Lehmiller et al., 2010; Rudman et al., 2007; Shrira \& Martin, 2005; Zârate \& Garza, 2002).

When examining the effects of self-affirmation on the proposed mediators, selfaffirmation had a significant effect on intergroup anxiety, compared to the control condition, $F(1,408)=5.58, p=.019$. Partially supporting Hypothesis II, participants in the self-affirmation condition $(M=3.33, S E=.14)$ reported lower levels of intergroup anxiety as compared to those in the control condition $(M=3.82, S E=.15), t(407)=-$ $2.36, p=.019$. This result was in the expected direction and suggested that for participants that wrote about the value most important to them, ratings of intergroup anxiety were lower as compared to participants that wrote about the value least important to them. Self-affirmation condition was not a predictor of self-compassion, $p=.873$; 
reports of self compassion were similar for the self-affirmation $(M=3.11, S E=.05)$ and control $(M=3.13, S E=.06)$ conditions. Hypothesis III was not supported. Given that prior research suggests that an important explanatory mechanism of self-affirmation is self-compassion and other positive self-directed feelings (e.g., Lindsay \& Cresswell, 2014; Schneider, 2018), this lack of an association was surprising.

\section{Post-Hoc Exploratory Analyses}

Because, contrary to predictions, self-affirmation condition had no effect on the outcomes and no effect on self-compassion, PROCESS models were not used to examine the mediational model depicted in Figure 1. Instead, in exploratory analyses, the influences of individual difference variables were explored as covariates in ANOVA models, along with self-affirmation, as predictors of the outcomes. Specifically, Z-scores of political ideology (higher scores indicated greater liberalism) and the coded-religion variable $(0=$ Christian, $1=$ Non-Christian $)$ were included as covariates of positive attitudes, negative attitudes, and feeling thermometers. Political ideology was correlated with religion $(r=.46, p<.01)$, such that higher levels of liberalism were associated with identifying as non-Christian, whereas lower levels of liberalism were associated with identifying as Christian. Variables involving the amount of time participants spent writing in their self-affirmation condition (time writing) and the number of words participants wrote (word count) were also included as covariates; these variables were correlated $(r=.54, p<.01)$. When comparing differences between time writing and word count, there was no difference between the self-affirmation $(M=99.72$ seconds, $S E=$ 5.84) and control condition $(M=100.79$ seconds, $S E=6.39)$ on the amount of time participants wrote, $t(407)=0.12, p=.904$; for word count, participants in the self- 
affirmation condition wrote a significantly larger amount of words $(M=44.15, S E=$ $1.91)$ as compared to participants in the control condition $(M=39.12, S E=1.51), t(407)$ $=-2.02, p=.044$. It was also examined whether there were effects of the order in which the measures were counterbalanced. Specifically, in separate ANOVA analyses, an order variable $(0=$ outcomes tested first, $1=$ mediators tested first $)$ and the self-affirmation conditions were examined for their simple and interactive effects on positive attitudes, negative attitudes, and feeling thermometers.

\section{Individual Differences and Self-Affirmation}

Self-affirmation condition, political ideology, and religion were examined for feeling thermometers, and a marginal effect for self-affirmation emerged in the predicted direction, $F(1,408)=3.65, p=.057$, such that those in the self-affirmation condition $(M$ $=51.35, S E=1.70)$ reported marginally more positive ratings of Muslims on the feeling thermometers as compared to those in the control condition $(M=46.54, S E=1.84)$, $t(407)=1.92, p=.056$. Additionally, political ideology was a significant predictor of feeling thermometers, $F(1,408)=10.97, p=.001$, such that higher levels of liberalism were associated with higher ratings of Muslims on the feeling thermometers as compared to lower levels of liberalism, $t(403)=3.31, p=.056$. Religion was also a significant predictor of responses on the feeling thermometers, $F(1,408)=31.50, p<.001$. Interestingly, Christians reported higher ratings of Muslims on the feeling thermometers as compared to non-Christians, $t(403)=-5.61, p<.001$. Time writing and word count were unrelated to feeling thermometers, $p \mathrm{~s} \geq .146$.

When examining effects of self-affirmation, political ideology, and religion on positive and negative attitudes, self-affirmation was not a significant predictor of positive 
$(p=.162)$ or negative attitudes $(p=.271)$. Those in the self-affirmation condition reported equivalent ratings of positive attitudes $(M=5.54, S E=.10)$ and negative attitudes $(M=4.32, S E=.11)$ as compared to those in the control condition (positive $M=$ 5.36, $S E=.11$, negative $M=4.49, S E=.11)$. Political ideology was a significant predictor of positive attitudes, $F(1,408)=12.05, p=.001$, and a marginally significant predictor of negative attitudes, $F(1,408)=2.73, p=.099$, such that as compared to those lower in liberalism, higher levels of liberalism were associated with more positive attitudes, $t(403)=3.47, p=.001$, and marginally less negative attitudes, $t(403)=-1.65, p$ $=.099$, toward Muslims. Religion was a significant predictor of positive attitudes, $F(1$, $408)=9.81, p=.002$, and unrelated to negative attitudes, $(p=.284)$. Christians expressed significantly more positive attitudes toward Muslims as compared to nonChristians, $t(403)=-3.13, p=.002$. Word count was a marginal predictor of positive attitudes, $F(1,408)=2.73, p=.099$, such that a larger number of words written (irrespective of self-affirmation or control condition) was associated with more positive attitudes toward Muslims, $t(403)=1.66, p=.098$. Word count was unrelated to negative attitudes, $p=.689$, and time writing was unrelated to positive and negative attitudes, $p \mathrm{~s} \geq$ .199 .

Including covariates in the analyses helped to clarify the pattern of results for feeling thermometer ratings. A marginal effect for self-affirmation condition emerged in the expected direction for feeling thermometers toward Muslims, such that those in the self-affirmation condition rated Muslims more positively on feeling thermometers as compared to those in the control condition, when accounting for political ideology and religion in the analysis. Self-affirmation condition continued to have no effect on positive 
and negative attitude ratings. Political ideology was a predictor of feeling thermometers, positive attitudes and (marginally for) negative attitudes, suggesting that higher levels of liberalism led to lower levels of prejudicial responding toward Muslims as compared to those lower in liberalism. In addition, religion was a predictor of feeling thermometers and positive attitudes; such that Christians reported higher ratings on feeling thermometers and positive attitudes as compared to non-Christians. These results suggest the importance of including these covariates to help clarify the effects of self-affirmation on these prejudice-related outcomes. Furthermore, these covariates were influential on the outcomes even when self-affirmation condition was not.

\section{Effects for Attitudes toward Atheists}

In another exploratory analysis, it was examined whether self-affirmation influenced attitudes toward Atheists on feeling thermometers, positive attitudes, and negative attitudes. Because attitudes toward outgroups were of interest in this work, Atheists $(N=83)$ were removed from the analyses; the analyses retained a religion variable that examined Christians $(N=238)$ as compared to non-Christian-non-Atheists $(N=88)$. A marginal effect of self-affirmation condition emerged for positive attitudes toward Atheists, $F(1,325)=3.52, p=.061$. Similar to results for feeling thermometers toward Muslims, participants in the self-affirmation condition reported marginally higher levels of positive attitudes toward Atheists $(M=5.73, S E=.11)$, as compared to those in the control condition $(M=5.43, S E=.12), t(324)=1.84, p=.066$. Self-affirmation was not a significant predictor of negative attitudes or feeling thermometers toward Atheists, $p s \geq .258$. Those in the self-affirmation condition gave equal ratings on negative attitudes $(M=4.49, S E=.11)$ and feeling thermometers $(M=55.90, S E=1.87)$ as compared to 
those in the control condition (negative $M=4.60, S E=.12$; feeling thermometers $M=$ 52.76, $S E=2.02)$.

In the same analyses examining attitudes toward Atheists, political ideology was a significant predictor of positive attitudes, $F(1,325)=6.88, p=.009$, negative attitudes, $F(1,325)=6.66, p=.010$, and feeling thermometers, $F(1,325)=29.38, p<.001$. That is, higher liberalism was associated with significantly more positive attitudes, $t(320)=$ 2.62, $p=.009$, significantly higher ratings on feeling thermometers, $t(320)=5.42, p<$ .001 , and significantly lower negative attitudes, $t(320)=-2.58, p=.010$, toward Atheists, as compared to those with lower levels of liberalism. Religion was a predictor only of feeling thermometers toward Atheists, $F(1,325)=5.97, p=.015$, and was unrelated to positive and negative attitudes, $p \mathrm{~s} \geq .452$. Christians reported significantly lower ratings on feeling thermometers toward Atheists as compared to non-Christian-non-Atheists, $t(320)=2.44, p=.015$. Time writing and word count were unrelated to feeling thermometers, positive attitudes, and negative attitudes toward Atheists, $p s \geq .248$.

When examining effects for attitudes toward Atheists, results for positive attitudes toward Atheists were similar to those of feeling thermometers toward Muslims. That is, those in the self-affirmation condition reported marginally higher positive attitudes toward Atheists as compared to those in the control condition. Similar to the results for feeling thermometers toward Muslims, including political ideology and religion in the analyses improved clarification of the findings on attitudes toward Atheists. Political ideology and religion (i.e., Christians vs. non-Christian-non-Atheists) were significant predictors of attitudes toward Atheists. Higher levels of liberalism led to higher ratings on positive attitudes and feeling thermometers, and lower negative attitudes, as compared to 
those lower in liberalism. Furthermore, religion was a predictor of feeling thermometers toward Atheists; Christians rated Atheists lower on feeling thermometers as compared to non-Christian-non-Atheists. These results suggest the importance of these covariates to understanding effects on the prejudice ratings toward Atheists.

\section{Order Effects}

Effects of counterbalancing and self-affirmation on the outcomes in an ANOVA analysis were also examined, and there was a significant effect of order on feeling thermometers, $F(1,408)=11.01, p=.001$, and positive attitudes, $F(1,408)=5.28, p=$ .022 , and a marginal effect on negative attitudes, $F(1,408)=3.63, p=.057$. When the mediators were tested prior to the outcomes, ratings of positive attitudes were higher ( $M$ $=5.63, S E=.11)$ as compared to instances where outcomes were tested prior to the mediators $(M=5.27, S E=.11), t(407)=2.43, p=.020$. Similarly, for feeling thermometers, ratings were higher when mediators $(M=53.21, S E=1.82)$ as compared to outcomes $(M=44.71, S E=1.80)$ were tested first, $t(407)=3.47, p=.001$. Negative attitudes were marginally lower when mediators $(M=4.25, S E=.11)$ as compared to outcomes $(M=4.55, S E=.11)$ were tested first, $t(407)=-1.96, p=.051)$. In these analyses, self-affirmation did not have a significant effect on the outcomes ( $p s \geq .122)$. When order was included in the model, ratings were similar in the self-affirmation condition for feeling thermometers $(M=50.95, S E=1.74)$, positive attitudes $(M=5.54$, $S E=.11)$, and negative attitudes $(M=4.32, S E=.11)$ as compared to ratings in the control condition (feeling thermometers $M=46.97, S E=1.88$, positive $M=5.36, S E=$ .11 , negative $M=4.48, S E=.11)$. Self-affirmation condition and order did not interact to predict responses on feeling thermometers, or positive or negative attitudes, $p s \geq .169$. 
When examining the effects of counterbalancing and self-affirmation condition on the mediators in an ANOVA analysis, there was a significant effect of order on intergroup anxiety, $F(1,408)=17.26, p<.001$, and no effect of order on selfcompassion $(p=.751)$. When the mediators were tested prior to the outcomes, ratings of intergroup anxiety were lower $(M=3.15, S E=.15)$ as compared to instances where the outcomes were tested prior to the mediators $(M=4.00, S E=.14), t(407)=-4.25, p<$ .001. When order was included in the analysis, self-affirmation condition was a significant predictor of intergroup anxiety, $F(1,408)=5.27, p=.022$, such that those in the self-affirmation condition $(M=3.34, S E=.14)$ reported lower levels of intergroup anxiety as compared to those in the control condition $(M=3.81, S E=.15), t(407)=-$ $2.29, p=.023$. Self-affirmation condition was not a predictor of self-compassion $(p=$ $.87)$; those in the self-affirmation condition reported equivalent ratings of selfcompassion $(M=3.11, S E=.05)$ as compared to those in the control condition $(M=3.13$, $S E=.06)$. Order and self-affirmation did not interact in predicting responses on intergroup anxiety or self-compassion, $p \mathrm{~s} \geq .284$.

Effects of counterbalancing led to differences on the feeling thermometers and positive attitude ratings, and marginally affected negative attitude ratings. Furthermore, counterbalancing led to differences on intergroup anxiety. The pattern of results suggested that when the mediators were tested prior to the outcomes, ratings on feeling thermometers and positive attitudes were higher, as compared to when the outcomes were tested prior to the mediators. Furthermore, negative attitudes were marginally lower (and intergroup anxiety was significantly lower) when the mediators were tested first, as compared to when the outcomes were tested first. 
It has been speculated through prior literature that measuring the mediating variables can disrupt or lead to the predicted process occurring (Spencer, Zanna, \& Fong, 2005). Measuring intergroup anxiety and self-compassion prior to the outcomes may have influenced the pattern of responses on the outcomes and intergroup anxiety. Because effects were stronger when intergroup anxiety and self-compassion were measured prior to the outcomes, it could be speculated that these measures may have influenced participants' responses in unintended ways. Specifically, the mediators may have primed participants to report lower levels of intergroup anxiety, which may have further led to reports of more socially desirable responses on the outcome measures. 


\section{Study 2}

Study 2 was designed to replicate, extend, and clarify the methods and results of Study 1. Specifically, Study 2 examined the capacity for self-affirmation to reduce prejudicial attitudes, and whether self-compassion and intergroup anxiety would mediate these relationships. Study 2 furthers the previous study by examining these relationships for a second type of outgroup (e.g., racial outgroup). African Americans, like Muslims, are a group that have been historically stigmatized in the U.S. Only White Americans were included in Study 2, because of an interest in examining outgroup attitudes in this work; specifically, White Americans' attitudes toward African Americans were of interest. Also, Study 2 incorporated an additional operationalization of prejudice, by examining positive job evaluation ratings for an outgroup (African American) or an ingroup (White American) candidate. The predicted results prior to data analyses are depicted in Figure 3. It was expected that there would be a significant condition $x$ candidate interaction on the prejudice-related outcomes (i.e., positive attitudes, negative attitudes, feeling thermometers, and job evaluation ratings). For the outgroup (African American) job candidate condition, it was expected that those in the self-affirmation condition would be significantly more likely to recommend the outgroup job candidate for hiring, and report lower levels of outgroup prejudice, as compared to those in the control condition. For the ingroup (White American) job candidate condition, it was expected that there would be no differences in hiring recommendations and prejudice ratings between the self-affirmation and control conditions (see Figure 3). These relationships were expected to be mediated by intergroup anxiety and self-compassion. Furthermore, group identification was expected as a moderator of two pathways: the 
pathway between self-affirmation and prejudice, and the pathway between selfaffirmation and intergroup anxiety.

\section{Method}

\section{Participants}

Participants were recruited via MTurk. Originally, $N=697$ MTurk workers participated in this study. Participants were removed from the dataset if they answered zero of four attention checks correctly $(N=6)$, identified as non-White $(N=14)$, or if they answered a manipulation check incorrectly $(N=48)$. In addition, one participant $(N$ $=1$ ) wrote a single word on the manipulation response (i.e., "good") and was therefore removed from the dataset. The resulting $N$ was 628 White American participants. A power analysis determined that a sample size of $N=501$ participants would be needed to obtain a power of .95 in order to detect a small effect of .20 , to examine main effects and interactions with four groups and one moderator. There were no duplicate IP addresses in the dataset. The majority of the sample identified as female $(N=377$; male $N=249$; other $N=2)$. The mean age of the sample was 38.79 years $(S D=11.73$, range of 18 to 76 years). Political ideology was measured on a 1 (strongly conservative) to 7 (strongly liberal) scale $(M=4.36, S D=1.81)$; in the sample, participants identified as very conservative, conservative, or slightly conservative $(N=199)$, moderate $(N=135)$, or slightly liberal, liberal, or very liberal $(N=294)$.

Participants were compensated with $\$ 1.00$ for their participation in this online experiment. Participants in Study 2 were paid $\$ 0.50$ more than participants in Study 1 because they completed a study with a similar study design, but which included an additional measure of prejudice (e.g., reviewing a job candidate profile and 
recommending a candidate for a job) and provided responses to additional measures. Study 2 methods and predicted results were preregistered on Open Science Framework as a separate preregistration from Study 1 (https://osf.io/n6am5); deviations from the preregistration (i.e., "exploratory analyses") are specified below.

\section{Procedure}

Study 2 used a 2 (condition: Self-Affirmation vs. Control) $\times 2$ (candidate: African American vs. White American) between-subjects design. Study 2 participants were randomly assigned to a self-affirmation or control condition. Participants were also randomly assigned to evaluate an ingroup candidate (White American) or an outgroup candidate (African American) for a job. Participants were assessed for intergroup anxiety, self-compassion, racial intergroup attitudes, job candidate evaluations, and group identification (see the Counterbalancing Procedure section below for clarification on the presentation of measures and manipulations). Upon completion of the study, participants were debriefed, thanked, and compensated online.

\section{Manipulations}

Self-affirmation. The self-affirmation manipulation was the same as the procedures used in Study 1.

Candidate. The candidate manipulation was adapted from previous selfaffirmation and prejudice research (e.g., Fein \& Spencer, 1997). All participants read about the qualifications of a male job candidate (Mark Williams) and asked to make an evaluative decision about whether they would hire that candidate for an entry-level job position (i.e., a Wish Coordinator for the non-profit Make-A-Wish Foundation). The job ad was presented to participants, and they were asked to familiarize themselves with the 
job ad. The job ad was adapted from a real online job posting for a Wish Coordinator through the Make-A-Wish Foundation.

After reading about the job posting, participants were provided with a purported LinkedIn online profile of a job candidate, which listed their qualifications for the position in question (i.e., education, work experience, skills, and awards). Half of the participants were randomly assigned to evaluate an outgroup job candidate (African American); the other half of participants evaluated an ingroup job candidate (White American). Following prior literature, the job candidate was represented as "fairly well qualified for the position, but not necessarily a stellar candidate" (Fein \& Spencer, 1997, pp. 33); in other words, the profile was designed to represent a moderately qualified candidate. LinkedIn profile information was adapted from previous materials posted by other researchers on Open Science Framework (i.e., https://osf.io/bcf2e/) and also taken from reviewing real LinkedIn profiles. In addition, a person with similar educational experience as the purported candidates, and who also works as an Academic Coordinator with student athletes at a university (assisting athletes with professional development and reviewing student résumés), provided feedback on candidate qualifications to ensure candidates were presented as moderately qualified. Furthermore, candidate qualifications were pretested with a sample of undergraduates $(N=12)$, and pretesting results suggested that the candidate qualifications were moderately qualified for the Wish Coordinator position (see Appendix B for the pretesting results for the candidate qualifications).

The African and White American candidates had the same qualifications (e.g., education, work history) and their LinkedIn profiles presented the same information; the only differences between the candidates was their ethnicity, as manipulated by a 
purported picture of the candidate on their purported LinkedIn profile. Photos for the purported job candidates were chosen from the Chicago Face Database (Ma, Correll, \& Wittenbrink, 2015). ${ }^{7}$ As a cover story, participants were told they would rank one candidate chosen randomly from a sample of ten possible candidates. In actuality, all participants evaluated one of two candidates: an ingroup (White American) or an outgroup (African American) candidate, with the exact same name and qualifications. The job ad, candidate profiles, and other study measures and manipulations for Study 2 are included in Appendix C.

\section{Measures}

Measures of positive attitudes $(\alpha=.96)$, negative attitudes $(\alpha=.89)$, feeling thermometers $(\alpha=.89)$, intergroup anxiety $(\alpha=.96)$, and self-compassion $(\alpha=.89)$, were the same used as in Study 1, except that the intergroup measures in Study 2 considered attitudes toward African Americans instead of Muslims. Additional nuances for Study 2 measures are explained below.

Candidate evaluation. Study 2 also included a measure of outgroup prejudice as operationalized by evaluation of an outgroup job candidate (vs. an ingroup candidate). Participants' ratings of the job candidate's qualifications (i.e., job evaluation ratings) were measured using the four evaluation items used in Fein \& Spencer (1997): "I feel this person would make an excellent candidate for the position in question," "I would likely give this person serious consideration for the position in question," "I would guess that

\footnotetext{
${ }^{7}$ Photos chosen were BM-232 \& WM-254 from the Chicago Face Database. Photos were chosen because they were equivalent on ratings reported by CFD; specifically, ratings $(1=$ strongly disagree, $7=$ strongly agree) of masculinity $(4.84,4.81)$, dominance $(3.20,3.23)$, attractiveness $(3.16,3.15)$, threatening $(1.96$, $2.00)$, trustworthiness $(3.20,3.23)$, number of raters that rated the faces $(N=25, N=26)$, and self-reported age (as reported by the person in the photo; 31.32 years, 30.31 years).
} 
this person is in the top $20 \%$ of people interviewed," and "I felt favorably toward this person" (1= strongly disagree; $7=$ strongly agree, $\alpha=.93)$.

Group identification. Study 2 included a measure of group identification. The 4item importance to identity subscale of the Collective Self-Esteem scale was used (Luhtanen \& Crocker, 1992). The race-specific version of the scale was used to examine the importance of one's identity as a White American. An example item includes "The racial/ethnic group I belong to is an important reflection of who I am" ( 1 = strongly disagree $; 7$ strongly agree, $\alpha=.85)$.

Motivation to control prejudice. Study 2 also included a three-item motivation to control prejudice measure used as a covariate. This measure was shortened from the five-item internal subscale of the Motivation to Control Prejudice scale (Plant \& Devine, 1998). The measure was reduced from five to three items to reduce participant burden and study length. The three included items were: "Being nonprejudiced toward Black people is important to my self-concept," "I attempt to act in nonprejudiced ways toward Black people because it is personally important to me," and "Because of my personal values, I believe that using stereotypes about Black people is wrong," ( 1 = strongly disagree, $9=$ strongly agree; $\alpha=.86)$.

\section{Statistical Analyses}

First, in a regression analysis, condition $(1=$ self-affirmation; $0=$ control $)$, job candidate $(1=$ African American; $0=$ White American $)$, and their interaction were examined for their effects on positive attitudes, negative attitudes, feeling thermometers, and job evaluation ratings. Next, if self-affirmation, candidate condition, and their interaction had a significant effect on the outcomes, mediators, and moderator, to test the 
theoretical model depicted in Figure 2, the PROCESS macro (Version 3; Hayes, 2013) would be used to determine the parallel mediational influences of intergroup anxiety and self-compassion, and the moderating influences of group identification, on the four prejudice-related outcomes. Group identification would be examined as a moderator of two pathways: the path between self-affirmation and intergroup anxiety, and the path between self-affirmation and outgroup attitudes. Predicted results prior to analyses are depicted in Figure 3. Finally, if self-affirmation, candidate condition, and their interaction were unrelated to the outcomes, mediators, or moderator, covariates including political ideology (higher scores mean higher levels of liberalism) and motivation to control prejudice (higher scores mean higher levels of motivation to control prejudice) were explored for their influences on these relationships. For example, it could be speculated that motivation to control prejudice may influence prejudice ratings toward African Americans, given that, in prior research, higher levels of motivation to control prejudice are associated with lower levels of prejudice. Table 2 shows the zero-order correlations among primary variables in Study 2.

\section{Counterbalancing Procedure}

The measures were counterbalanced in Study 2, and presentation of measures and manipulations to participants were as follows. First, all participants engaged in the selfaffirmation or control (between-subjects) writing manipulation. Half of the participants were then presented with the mediators, followed by the job candidate (between-subjects) manipulation and prejudice-related outcome measures. The other half of participants were presented with the job candidate (between-subjects) manipulation and prejudicerelated outcome measures, and this was followed by the mediators. Due to procedural 
error, reviewing the job candidate and the job evaluation rating measures were counterbalanced as explained above, rather than always being measured following the self-affirmation manipulation and prior to the other measures; this was unintentional. The moderator (collective self-esteem) was measured next, followed by motivation to control prejudice and the demographic variables (including political ideology). For the mediators in Study 2, intergroup anxiety was always measured prior to self-compassion. The order

of the outcomes were: job evaluation ratings, then feeling thermometers, and positive and negative attitudes were presented mixed together. An order variable $(1=$ mediators tested prior to outcomes, $0=$ outcomes tested prior to mediators) would be explored if there were significant effects of counterbalancing on the outcomes. In other words, it was explored whether mediators tested first (vs. outcomes tested first) had an effect on the study results. This counterbalancing procedure led to one of eight possible combinations of measures: or, a counterbalancing procedure of self-affirmation (self-affirmation vs. control) $\times$ candidate $($ African American vs. White American) $\times$ order (mediators first vs. outcomes first).

\section{Results and Discussion}

\section{Self-Affirmation, Candidate, and their Interaction}

Outcomes. The effects of self-affirmation, candidate, and their interaction were examined in an ANOVA analysis, and a marginal self-affirmation $\times$ candidate interaction emerged predicting positive attitudes, $F(1,627)=3.67, p=.056$. For participants in the White American candidate condition, those in the self-affirmation condition reported similar levels of ratings toward African Americans $(M=6.60, S E=.13)$ as compared to those in the control condition $(M=6.90, S E=.13), t(310)=-1.63, p=.104$, although the 
mean for the control condition was higher. For participants in the African American candidate condition, those in the self-affirmation condition reported similar levels of ratings toward African Americans $(M=6.93, S E=.12)$ as compared to those in the control condition $(M=6.75, S E=.12), t(314)=1.05, p=.297$, although the mean for the self-affirmation condition was higher. The main effects for self-affirmation and candidate conditions were not significant, $p s \geq .48$. These results for positive attitudes were similar to hypotheses. In particular, it was expected that for those in the African American candidate condition, those in the self-affirmation condition would show higher levels of positive attitudes as compared to the control condition; it was further expected that in the White American candidate condition, there would be no differences between the selfaffirmation and control conditions. Although there was not a significant difference between the self-affirmation and control conditions in the African American candidate condition, the mean rating was higher (although not significantly higher) for the selfaffirmation condition when comparing it to the control condition.

When examining the effects for negative attitudes, the main effects for selfaffirmation, candidate, and their interaction were not significant, $p \mathrm{~s} \geq .166$. For the selfaffirmation condition, ratings of negative attitudes toward African Americans were equivalent for those in the White American $(M=4.04, S E=.14)$ and African American $(M=4.19, S E=.14)$ candidate conditions. For the control condition, ratings of negative attitudes toward African Americans were equivalent for those in the White American ( $M$ $=4.11, S E=.15)$ and African American $(M=3.86, S E=.15)$ candidate conditions.

Results for feeling thermometers were similar to those for negative attitudes. When examining effects for feeling thermometers toward African Americans, the main 
effects of the conditions and their interactions were not significant, $p s \geq .420$. For the self-affirmation condition, ratings of feeling thermometers toward African Americans were equivalent for those in the White American $(M=69.01, S E=1.64)$ and African American $(M=71.77, S E=1.64)$ candidate conditions. For the control condition, ratings of feeling thermometers toward African Americans were equivalent for those in the White American $(M=70.01, S E=1.74)$ and African American $(M=70.06, S E=1.72)$ candidate conditions. The findings for negative attitudes and the feeling thermometers were inconsistent with predictions; it was expected that there would be a significant selfaffirmation $\times$ candidate interaction. The lack of an effect on these conditions for these outcomes were inconsistent with the marginal effects found for positive attitudes, and were surprising, given prior research which suggests that self-affirmation can lead to lower levels of prejudice.

When examining effects for ratings of job candidate evaluations, a main effect emerged for candidate condition, $F(1,627)=53.14, p<.001$. Participants in the African American candidate condition evaluated the job candidate as more qualified $(M=5.08$, $S E=.07)$ as compared to participants in the White American candidate condition $(M=$ $4.32, S E=.07)$, irrespective of self-affirmation condition, $t(626)=7.31, p<.001$. The effect of self-affirmation and the interaction between self-affirmation and candidate conditions were not significant, $p \mathrm{~s} \geq .119$. These findings were not consistent with the proposed self-affirmation $\times$ candidate interaction that was expected prior to analyses.

Mediators. Self-affirmation, candidate, and their interaction were examined for their effects on the mediators, and no significant effects emerged for intergroup anxiety toward African Americans, all $p \mathrm{~s} \geq$.339. In other words, for the self-affirmation 
condition, ratings of intergroup anxiety toward African Americans were equivalent for those in the White American $(M=2.65, S E=.14)$ and African American $(M=2.70, S E=$ .14) candidate conditions. For the control condition, ratings of intergroup anxiety were equivalent for those in the White American $(M=2.46, S E=.147)$ and African American $(M=2.69, S E=.145)$ candidate conditions. These results were unexpected; it was previously hypothesized that the self-affirmation condition would lead to lower levels of intergroup anxiety as compared to the control condition, irrespective of candidate condition. Surprisingly, the conditions had no effect on intergroup anxiety, suggesting that intergroup anxiety was unaffected by reading about an African or White American job candidate, or writing about values that a person identifies as the most or least important value to themself.

For self-compassion, there was a significant self-affirmation $\times$ candidate interaction, $F(1,627)=4.95, p=.027$. For the control condition, participants in the African American $(M=3.09, S E=.06)$ and White American $(M=3.11, S E=.06)$ candidate conditions reported no differences in self-compassion, $t(294)=0.22, p=.83$. For the self-affirmation condition, those in the African American candidate condition reported lower levels of self-compassion $(M=2.99, S E=.06)$ as compared to those in the White American candidate condition $(M=3.25, S E=.06), t(330)=-2.91, p=.004$. A marginal main effect also occurred for candidate condition in this analysis, $F(1,627)=$ 3.68, $p=.055$, such that those in the White American candidate condition reported higher levels of self-compassion $(M=3.17, S E=.04)$ as compared to those in the African American candidate condition $(M=3.05, S E=.04)$, regardless of self-affirmation condition, $t(626)=-2.05, p=.041$. These results were surprising; it was expected that 
those in the self-affirmation condition would report higher levels of self-compassion as compared to the control condition, irrespective of candidate condition. Instead, the results suggested that for the self-affirmation condition, evaluating an African American job candidate led to lower ratings of self-compassion as compared to those that evaluated a White American job candidate.

Moderator. Self-affirmation, candidate, and their interaction had no effect on collective self-esteem, $p \mathrm{~s} \geq .516$. In addition, collective self-esteem was not a significant predictor of any of the four prejudice-related outcomes, $p s \geq .145$. Relatedly, when examining the two-way interactions between collective self-esteem and the conditions, collective self-esteem did not interact with self-affirmation condition ( $p \mathrm{~s} \geq .579)$, or candidate condition ( $p \mathrm{~s} \geq .113)$ to affect the outcomes. Finally, the self-affirmation $\times$ candidate $\times$ collective self-esteem interaction had no significant effect on the outcomes ( $p \mathrm{~s} \geq .166$ ). Given prior theory and research, which suggests that group identification can moderate the association between self-affirmation and prejudice outcomes (e.g., Adams et al., 2006; Badea \& Sherman, 2019; Cohen et al., 2007; Sherman et al., 2007), these results were surprising.

\section{Post-Hoc Exploratory Analyses}

Because, contrary to predictions, self-affirmation condition, candidate condition, and their interaction were mostly unrelated to the outcomes and explanatory mechanisms (i.e., intergroup anxiety, collective self-esteem, collective self-esteem), PROCESS models were not used to examine the mediational model depicted in Figure 2. Instead, in exploratory analyses, ANOVA models in which the effects for the self-affirmation condition, candidate condition, and their interaction were explored, while incorporating 
individual differences as predictors of the outcomes. Specifically, a Z-score for political ideology (higher scores mean higher levels of liberalism) and a Z-score for motivation to control prejudice (higher scores mean more motivation to control prejudice) were included as covariates of feeling thermometers, positive attitudes, negative attitudes, and job evaluation ratings. Political ideology was correlated with motivation to control prejudice $(r=.30, p<.01)$, such that higher levels of liberalism were associated with higher levels of motivation to control prejudice, as compared to lower levels of liberalism. Variables involving the amount of time participants spent writing in their condition (time writing) and the number of words participants wrote (word count) were also included as covariates; these variables were correlated $(r=.39, p<.01)$. When comparing differences between time writing and word count, participants in the selfaffirmation condition wrote for a significantly longer amount of time $(M=120.25$ seconds, $S E=9.15)$ as compared to the control condition $(M=98.31$ seconds, $S E=4.32)$, $t(626)=-2.09, p=.037$; for word count, participants in the self-affirmation condition wrote a significantly larger amount of words $(M=48.19, S E=1.47)$ as compared to participants in the control condition $(M=39.83, S E=1.26), t(626)=-4.27, p<.001 .^{8} \mathrm{It}$ was also examined whether there were effects of counterbalancing of the measures on the outcomes. Specifically, in separate ANOVA analyses, an order variable $(1=$ mediators tested first, $0=$ outcomes tested first) and the conditions were examined for their main

\footnotetext{
${ }^{8}$ An ANOVA analysis with self-affirmation condition, candidate condition, and their interaction was conducted with time writing and word count as the outcome variables. Candidate condition had no effect on time writing or word count, $p s \geq .329$. And, the self-affirmation $\times$ candidate interaction had no effect on time writing and word count, $p \mathrm{~s} \geq .518$. To simplify results for time writing and word count, simple $t$-tests are presented above with self-affirmation condition predicting time writing and word count.
} 
effects, two-way, and three-way interactive effects on feeling thermometers, positive attitudes, negative attitudes, and job evaluation ratings.

\section{Individual Differences and Conditions}

When controlling for the effects of political ideology, motivation to control prejudice, time writing, and word count, a significant self-affirmation $\times$ candidate interaction emerged for positive attitudes toward African Americans, $F(1,627)=6.37, p$ $=.012$. As shown in Figure 4, for participants in the White American candidate condition, those in the self-affirmation condition reported similar levels of ratings toward African Americans $(M=6.69, S E=.10)$ as compared to those in the control condition $(M=6.90$, $S E=.11), t(294)=-1.42, p=.158$, although the mean for the control condition was higher. For participants in the African American candidate condition, those in the selfaffirmation condition reported higher levels of positive attitudes toward African Americans $(M=6.95, S E=.10)$ as compared to those in the control condition $(M=6.63$, $S E=.11), t(330)=2.15, p=.032$. Motivation to control prejudice was a significant predictor of positive attitudes toward African Americans, $F(1,627)=197.50, p<.001$. Higher levels of motivation to control prejudice were associated with higher positive attitudes as compared to those with lower levels of motivation to control prejudice, $t(620)$ $=14.05, p<.001$. The main effects for self-affirmation condition, $p=.613$, and candidate condition, $p=.965$, were not significant. Political ideology was unrelated to positive attitudes toward African Americans, $p=.294$. Time writing and word count were unrelated to positive attitudes, $p \mathrm{~s} \geq .344$.

When effects for negative attitudes were examined, self-affirmation, candidate, and their interaction were not significant predictors of negative attitudes, $p \mathrm{~s} \geq .190$. For 
the self-affirmation condition, ratings of negative attitudes toward African Americans were equivalent for those in the White American $(M=3.98, S E=.13)$ and African American $(M=4.19, S E=.13)$ candidate conditions. For the control condition, ratings of negative attitudes toward African Americans were equivalent for those in the White American $(M=4.09, S E=.14)$ and African American $(M=3.95, S E=.14)$ candidate conditions. Motivation to control prejudice, $F(1,627)=68.69, p<.001$, and political ideology, $F(1,627)=6.75, p=.010$, emerged as significant predictors for negative attitudes. Participants who reported higher levels of motivation to control prejudice reported significantly less negative attitudes toward African Americans as compared to those with lower levels of motivation to control prejudice, $t(620)=-8.29, p<.001$. Also, higher levels of liberalism were associated with significantly less negative attitudes as compared to those with lower levels of liberalism, $t(620)=-2.60, p=.010$. Time writing and word count were unrelated to negative attitudes, $p s \geq .107$.

Self-affirmation, candidate, and their interaction had no significant effects for feeling thermometers, $p \mathrm{~s} \geq .240$. For the self-affirmation condition, ratings of feeling thermometers toward African Americans were equivalent for those in the White American $(M=69.99, S E=1.46)$ and African American $(M=72.14, S E=1.45)$ candidate conditions. For the control condition, ratings of feeling thermometers toward African Americans were equivalent for those in the White American $(M=69.95, S E=$ 1.55) and African American $(M=68.61, S E=1.54)$ candidate conditions. Motivation to control prejudice emerged as a significant predictor for feeling thermometers, $F(1,627)=$ $167.98, p<.001$, and political ideology emerged as a marginal predictor, $F(1,627)=$ $3.18, p=.075$. Participants who reported higher levels of motivation to control prejudice 
reported significantly higher ratings on feeling thermometers toward African Americans as compared to those with lower levels of motivation to control prejudice, $t(620)=12.96$, $p<.001$. In addition, when controlling for other variables in the model, increases in liberalism were associated with marginally lower ratings on feeling thermometers toward African Americans as compared to those lower in liberalism, $t(620)=-1.78, p=.075$. Time writing was a marginally significant predictor of feeling thermometers, $F(1,627)=$ 2.86, $p=.092$, such that higher amounts of time writing in the conditions was associated with marginally lower ratings on the feeling thermometers, as compared to lower amounts of writing, $t(620)=-1.69, p=.092$. Word count was unrelated to feeling thermometers, $p=.727$.

When considering effects for ratings of job candidate evaluations, there was a main effect for candidate condition, $F(1,627)=52.67, p<.001$. As reported previously, participants in the African American candidate condition gave significantly higher job evaluations to the candidate $(M=5.08, S E=.07)$ as compared to participants in the White American candidate condition $(M=4.32, S E=.07)$, irrespective of selfaffirmation condition, $t(620)=4.99, p<.001$. Motivation to control prejudice was a significant predictor of evaluations, $F(1,627)=7.07, p=.008$, but political ideology was not, $p=.381$. Participants who reported higher ratings of motivation to control prejudice reported significantly higher ratings on job evaluations as compared to those with lower levels of motivation to control prejudice, $t(620)=2.66, p=.008$. Time writing and word count were unrelated to job evaluation ratings, $p \mathrm{~s} \geq .171$.

Including covariates in the analyses largely clarified the results for positive attitudes and job evaluation ratings (outcomes which showed marginal or significant 
effects with the study manipulations). A significant self-affirmation $\times$ candidate interaction emerged in the expected direction for positive attitudes, when accounting for motivation to control prejudice and political ideology in the analysis. Furthermore, a significant effect of candidate condition remained for job evaluation ratings, when accounting for motivation to control prejudice and political ideology. Both covariates showed influences on the outcomes. Political ideology was a predictor of negative attitudes and feeling thermometer ratings. Motivation to control prejudice was a significant and consistent predictor of all four outcomes. These results suggest the importance of including these variables to help clarify the effects of the conditions and their interaction on the prejudice-related outcomes. Furthermore, these covariates were influential on all four outcomes (positive and negative attitudes, feeling thermometers, and job evaluation ratings) even when self-affirmation condition, candidate condition, and their interaction were not.

\section{Order Effects}

Counterbalancing was examined by including the self-affirmation condition, candidate condition, and order $(1=$ mediators measured before outcomes, $0=$ outcomes measured before mediators) into an ANOVA analysis. The main effects of selfaffirmation condition, candidate condition, order, and all two- and three-way interactions were examined for their effects on positive attitudes, negative attitudes, feeling thermometers, and job evaluation ratings.

Effects of counterbalancing, self-affirmation, and candidate conditions were examined on the outcomes in an ANOVA analysis, and there was a significant effect of order on feeling thermometers only, $F(1,627)=4.00, p=.046$; when the mediators were 
tested prior to the outcomes, ratings of feeling thermometers toward African Americans were higher $(M=71.93, S E=1.19)$ as compared to when the outcomes were tested prior to the mediators $(M=68.57, S E=1.19), t(626)=1.97, p=.0496$. Order was not a significant predictor of positive attitudes, negative attitudes, or job evaluation ratings, $p \mathrm{~s}$ $\geq .331$.

When examining two-way interactions with order and the conditions, the selfaffirmation $\times$ order interaction was not a significant predictor of any of the four outcomes, $p s \geq .376$. The candidate $\times$ order interaction was marginally significant for feeling thermometers, $F(1,627)=3.72, p=.054$, and job candidate evaluations, $F(1$, $627)=2.75, p=.098$. For feeling thermometers, in the White American candidate condition, there appeared to be no differences in feeling thermometers toward African Americans as a function of whether mediators were tested first $(M=69.55, S E=1.67)$ or outcomes were tested first $(M=69.43, S E=1.71), t(310)=0.04, p=.97$. For those in the African American candidate condition, ratings on feeling thermometers were higher when the mediators were tested first $(M=74.31, S E=1.69)$ as compared to when the outcomes were tested first $(M=67.70, S E=1.66), t(314)=2.90, p=.004$. When examining job candidate evaluations, a similar pattern of results emerged. In the White American candidate condition, there appeared to be no differences in job evaluations as a function of whether the mediators $(M=4.29, S E=.10)$ or the outcomes $(M=4.36, S E=$ .11) were tested first, $t(310)=-0.42, p=.672$; in the African American candidate condition, ratings of job evaluations were higher when the mediators were tested prior to the outcomes $(M=5.22, S E=.10)$ as compared to when the outcomes were tested prior 
to the mediators $(M=4.95, S E=.10), t(314)=1.99, p=.047$. The candidate $\times$ order interaction was not significant for positive or negative attitudes, $p s \geq .300$.

The self-affirmation $\times$ candidate $\times$ order interaction was not significant for any of the four outcomes, $p \mathrm{~s} \geq .517$. In addition, including order in the analysis did not remove the effects for the conditions. That is, when order was included in the model, the selfaffirmation $\times$ candidate interaction marginally predicted positive attitudes, $F(1,627)=$ 3.52, $p=.061$, and candidate significantly predicted job evaluation ratings, $F(1,627)=$ $53.50, p<.001$.

Order was a significant predictor of intergroup anxiety, $F(1,627)=9.12, p=$ .003 , and not a significant predictor of self-compassion, $p=.277$. Ratings of intergroup anxiety toward African Americans were lower when the mediators were tested first $(M=$ 2.83, $S E=.10)$ as compared to when the outcomes were tested first $(M=2.41, S E=.10)$, $t(626)=-3.09, p=.002$. The self-affirmation $\times$ order interaction did affect intergroup anxiety or self-compassion, $p \mathrm{~s} \geq .771$. The candidate $\times$ order interaction predicted intergroup anxiety, $F(1,627)=3.92, p=.048$, and did not predict self-compassion, $p=$ .508. When examining intergroup anxiety, the pattern of results suggested that in the White American condition, there were no differences in intergroup anxiety when the mediators were tested prior to the outcomes $(M=2.48, S E=.14)$ as compared to when the outcomes were tested prior to the mediators $(M=2.63, S E=.14), t(310)=-0.74, p=$ 458. In the African American candidate condition, intergroup anxiety was lower when the mediators were tested first $(M=2.33, S E=.14)$ as compared to when the outcomes were tested first $(M=3.04, S E=.14), t(314)=-3.69, p<.001$. The self-affirmation $\times$ 
candidate $\times$ order interaction did not significantly predict intergroup anxiety or selfcompassion, $p \mathrm{~s} \geq .589$.

Effects of counterbalancing led to differences on two of the outcomes (feeling thermometers and job evaluation ratings) and one of the mediators (intergroup anxiety). For feeling thermometers and intergroup anxiety, a main effect of order was significant; when the mediators were tested first, ratings of feeling thermometers were higher, and ratings of intergroup anxiety were lower, as compared to when the outcomes were tested first. There was a marginal interaction with counterbalancing and candidate condition on feeling thermometers and job evaluation ratings, and a significant interaction predicting intergroup anxiety. For both outcomes, the pattern of results suggested that for those in the African American candidate condition, feeling thermometers toward African Americans and job evaluation ratings were higher when the mediators were tested first as compared to when the outcomes were tested first. Mirroring the pattern for feeling thermometers and job evaluation ratings, for those that evaluated an African American job candidate, ratings of intergroup anxiety were lower when intergroup anxiety and selfcompassion were tested prior to the job evaluation ratings, feeling thermometers, and attitudes measures, as compared to instances when the outcomes were tested prior to intergroup anxiety and self-compassion. There appeared to be no influences of order in the White American candidate condition for feeling thermometers, job evaluation ratings, and intergroup anxiety.

As discussed in Study 1, it has been speculated through prior literature that measuring the mediating variables can disrupt or lead to the predicted process occurring (Spencer, Zanna, \& Fong, 2005). Measuring intergroup anxiety and self-compassion prior 
to the outcomes may have influenced the pattern of responses. Because order effects had a marginal interaction with candidate condition, it could be speculated that for those in the African American candidate condition, measuring intergroup anxiety and selfcompassion prior to the job candidate manipulation, job evaluation ratings, and the other attitudes measures may have influenced participants' responses; in this case, the mediators may have primed participants to report lower levels of intergroup anxiety, which may have further led to reports of more socially desirable responses on the outcome measures. 


\section{General Discussion}

Prior research has suggested that self-affirmation can reduce outgroup prejudice (Badea \& Sherman, 2019; Binning, Sherman, Cohen, \& Heitland, 2010; Cohen, Sherman, Bastardi, Hsu, McGoey, \& Ross, 2007; Fein \& Spencer, 1997; Kinias \& Fennessy, 2016; Rudman et al., 2007; Shrira \& Martin, 2005; Zârate \& Garza, 2002). Prior research has also shown that these effects may be mediated (Kinias \& Fennessy, 2016; Shrira \& Martin, 2005) or moderated (Badea et al., 2018; Cohen et al., 2007; Sherman et al., 2007) by explanatory variables. The current studies were designed to examine the effects of self-affirmation on prejudice, and to identify relevant mediators and moderators of this effect. Study 1 examined the effect of providing participants an opportunity to self-affirm their values, compared to a control condition, on three prejudice-related outcomes toward Muslims and Atheists (e.g., feeling thermometers, and positive and negative attitudes). Study 2 examined the effect of this same self-affirmation condition on evaluations of an African American or White American job candidates, and the interaction between these manipulations on positive attitudes, negative attitudes, feeling thermometers toward African Americans, and job evaluation ratings toward an ingroup or an outgroup candidate.

\section{Study 1}

In Study 1, among a sample of White non-Muslim U.S. adults, there was no effect of the self-affirmation condition as compared to the control condition, on the outcomes designed to measure prejudice toward Muslims. These results were surprising, given that prior research has shown that self-affirmation leads to higher levels of outgroup attitudes. When exploring self-affirmation and its effect on the proposed mediators, self- 
affirmation had no effect on self-compassion and was a predictor of intergroup anxiety: those in the self-affirmation condition reported significantly lower levels of intergroup anxiety as compared to those in the control condition. No prior research has examined the effects of self-affirmation on intergroup anxiety, although the results were consistent with prior positive effects for self-affirmation on other outgroup attitudes measures. The lack of an effect of self-affirmation on self-compassion was surprising, given prior research which suggests that self-affirmation can improve self-directed positive feelings, which can have further positive downstream consequences regarding social relationships (Crocker et al., 2008; Lindsay \& Cresswell, 2014; Schneider, 2018).

In exploratory analyses, with political ideology and religion as covariates in the model, a marginal effect for self-affirmation condition emerged for the feeling thermometers; in this analysis, participants in the self-affirmation condition provided marginally higher ratings on the feeling thermometers toward Muslims as compared to those in the control condition, which was consistent with predictions. Similarly, when exploring attitudes toward Atheists among non-Atheists (i.e., those that would identify Atheists as an outgroup), a marginal effect for self-affirmation emerged for positive attitudes when political ideology and religion were included as covariates.

Interestingly, the effects of self-affirmation emerged for attitudes toward Muslims and Atheists when controlling for participants' political ideology and religious affiliation. Although no hypotheses were offered for these covariates, political ideology and religion showed strong but divergent influences on the prejudice outcomes toward Muslims. Political ideology had a significant or marginal effect on all of the outcomes, such that higher levels of liberalism were associated with more positive and less negative attitudes. 
Somewhat surprisingly, Christians gave higher ratings on feeling thermometers and positive attitudes toward Muslims as compared to Non-Christians. What these results suggest is that Christian participants (those that identified with a different religion than Muslims) were more likely to give positive ratings to Muslims as compared to NonChristians (those that largely identified as non-religious). These results were surprising for a couple of reasons. First, it is the case that Muslims receive negative media coverage in the United States, coupled with negative stereotypes that have existed toward Muslims for the past several decades (e.g., violent). It is also the case that Christians' attitudes have been reported as more negative toward Muslims as compared to other groups in prior research. For example, Pew Research Center (2017) found that among Americans, Christians reported lower ratings on feeling thermometers toward Muslims as compared to those unaffiliated with a religion (see also Rowatt et al., 2005, for similar findings in academic research). More consistent with Pew Research Center (2017), Christians in Study 1 reported less favorable attitudes toward Atheists as compared to non-Christiannon-Atheists (see also Simpson \& Rios, 2016, for similar findings in academic research).

Second, the results for Muslims and Atheists seem interesting when considering the influences of Christianity in U.S. culture. Although the U.S. Constitution emphasizes freedom of religion and there is, therefore, no official religion of the country, Christianity is the most practiced religion in the U.S., and it has had influences in many aspects of American culture (e.g., "In God We Trust" listed on currency, "Under God" included in the Pledge of Allegiance, placing a hand on the Bible to be sworn in in court proceedings and governmental positions). Moreover, religion is often highly politicized in the U.S., with conservatives identifying more strongly with Christianity, compared to liberals. 
Conservatism may be a more strong predictor of negative attitudes toward Muslims as compared to Christians. Perhaps the results can be explained by suggesting that conservatives and Christians separately viewed Muslims as a different type of outgroup, and perhaps Muslims are more threatening to conservatives as compared to Christians. Conservatives may view Muslims as a cultural outgroup (a group perceived by conservatives as holding values, norms, and practices inconsistent with the ingroup); the results would suggest that this cultural outgroup was perceived as strongly negative among conservative participants in Study 1. In contrast, perhaps Christians identified Muslims as a religious outgroup (a group that practices a different religion than the Christian ingroup); the results of Study 1 would suggest that although Christians view Muslims as religious outgroup members, attitudes toward this group appeared to be less negative as compared to responses from non-Christians, a finding that is inconsistent with ingroup bias literature. To perhaps explain these puzzling findings, Muslims, as a cultural outgroup, seem to pose a greater threat to conservatives (and therefore, led to more negative attitudes in Study 1), as compared to Christians' perceptions of Muslims as a religious outgroup.

\section{Study 2}

In Study 2, among a sample of White U.S. adults, a marginal interaction emerged between the self-affirmation and candidate conditions in a pattern similar to predictions for positive attitudes. For those in the African American candidate condition, positive attitudes toward African Americans tended to be higher in the self-affirmation as compared to the control condition. The reverse pattern emerged for those in the White American condition: positive attitudes toward African Americans were lower in the self- 
affirmation (as compared to control) condition. As expected, the combination of reviewing an African American candidate and self-affirmation led to reductions in outgroup prejudice: in this case, increases in positive attitudes. For job evaluation ratings, only a main effect of candidate condition emerged: the candidate was given a higher evaluation when the candidate was African American as compared to the White American candidate. These results for job evaluation ratings are a reversal of previous research, which typically shows when reviewing just one job candidate with moderate qualifications (either an ingroup or an outgroup candidate), ingroup members are given higher ratings for job evaluations as compared to outgroup members in the absence of self-affirmation (Fein \& Spencer, 1997). Furthermore, these results are inconsistent with a prior meta-analysis, which suggests that when evaluation criteria are ambiguous (e.g., ambiguous qualifications for a job), ratings of African Americans should be lower as compared to ratings for White Americans among samples of White Americans (Aberson \& Ettlin, 2004).

However, the results for candidate evaluation ratings are consistent with prior research on expectancy violation theory and the black sheep effect (Bettencourt et al., 2016; Biernat et al., 1999). Specifically, Bettencourt et al. (2016) found through metaanalytic evidence that when neutral information is presented about targets, but the information violates group norms, outgroup targets are evaluated more positively as compared to ingroup targets. In the context of Study 2, moderately qualified candidates were presented, which can be interpreted as relatively neutral information. That the African American candidate received higher evaluations as compared to the White American candidate suggests that an expectancy violation might have occurred. Perhaps, 
for example, the participants (who were all White American) expected that the White American candidate (an ingroup member) should be highly qualified for the job position, and because the candidate was, instead, only moderately qualified, ratings of this candidate were lower as compared to those of the African American candidate (with the same qualifications). Furthermore, the manipulations had no effect on negative attitudes or the feeling thermometers.

When examining relationships with the proposed mediators and moderator, unlike in Study 1, self-affirmation condition, candidate condition, and their interaction had no effect on intergroup anxiety; for self-compassion, these variables interacted in predicting self-compassion. In the self-affirmation condition, self-compassion was significantly lower in the African American condition as compared to the White American candidate condition. In the control condition, however, there were no differences in selfcompassion as a function of self-affirmation condition. These results were not predicted prior to analyses and were surprising; it was previously predicted that a main effect of self-affirmation would emerge for self-compassion.

As reported in Study 2, the conditions and their interaction were unrelated to collective self-esteem, collective self-esteem was not a significant predictor of any of the four outcomes, and collective self-esteem did not interact with the conditions (in any of the two-way or the three-way interactions) to affect the four outcomes. Furthermore, results were not changed, or effects removed, when collective self-esteem was included in the model. Given prior theory and research, which suggests that group identification can moderate the association between self-affirmation and prejudice outcomes (e.g., 
Adams et al., 2006; Badea \& Sherman, 2019; Cohen et al., 2007; Sherman et al., 2007), this lack of an effect for collective self-esteem on the outcomes was surprising.

Similar to Study 1, including covariates in the analyses for Study 2 appeared to clarify the effects of the manipulations. When controlling for motivation to control prejudice and political ideology, the prior reported marginal interaction between selfaffirmation condition and candidate condition emerged as a significant interaction for positive attitudes toward African Americans. Specifically, the marginal interaction became significant when controlling for motivation to control prejudice and political ideology. In addition, the main effect of candidate predicting job evaluation ratings remained significant when including covariates in the model. Similar to Study 1, political ideology was a significant predictor of negative attitudes and feeling thermometers toward African Americans. When controlling for motivation to control prejudice, higher levels of liberalism were associated with less negative attitudes and marginally lower ratings on feeling thermometers as compared to lower levels of liberalism. It is important to note that when examining political ideology as a single predictor of feeling thermometers, increases in liberalism was associated with higher ratings on feeling thermometers. The reversal of this pattern may suggest a trend of a suppression effect in Study $2^{9}$. Indeed, motivation to control prejudice was a strong and consistent predictor of more positive attitudes toward African Americans, regardless of the outcome variable, in

\footnotetext{
${ }^{9}$ A suppression effect occurs when 1) two predictors are strongly correlated (such as motivation to control prejudice and political ideology, $r=.30, p<.01), 2$ ) one predictor has a robust, positive correlation with the outcome (motivation to control prejudice is correlated with feeling thermometers, $r=.46, p<.01$ ), 3 ) one predictor has a weak correlation with the outcome (political ideology is weakly correlated with feeling thermometers, $r=.08, p<.05), 4) \mathrm{R}^{2}$ is strong and larger than $.50\left(\mathrm{R}^{2}=.223\right.$ for feeling thermometers $)$, and 5) $\beta$ is significantly negative predicting the outcome (for political ideology, $\beta=-.066, p=.075$ ). Given the marginal significance of political ideology and the $\mathrm{R}^{2}=.223$ for the model for feeling thermometers, this would suggest a trend of (but not a significant effect of) a suppressor effect of political ideology.
} 
Study 2. Motivation to control prejudice was associated with higher positive attitudes, feeling thermometer ratings, job evaluation ratings, and lower negative attitudes, irrespective of the self-affirmation or candidate conditions. As has been shown in prior literature (e.g., Butz \& Plant, 2009; Plant \& Devine, 2009), motivation to control prejudice toward African Americans had strong, negative relationships with the prejudice-related outcomes in Study 2.

\section{Effects of Counterbalancing in Studies 1 and 2}

Order effects were present in both Studies 1 and 2 (see "Counterbalancing Procedure" in the methods sections of Studies 1 and 2 for descriptions of the counterbalancing procedures). When the mediators were tested prior to the outcomes, positive attitudes were higher, and prejudice was lower, as compared to when the outcomes were tested prior to the mediators. In Study 1, testing the mediators first led to higher ratings on the feeling thermometers and positive attitudes (and marginally less negative attitudes) as compared to when the outcomes were tested first. In Study 2, the mediators tested first led to significantly higher ratings on feeling thermometers and lower ratings on intergroup anxiety toward African Americans, as compared to when the outcomes were tested first. In addition, order and candidate condition interacted in predicting feeling thermometers, job evaluation ratings, and intergroup anxiety. In the African American candidate condition, when the mediators were tested first, ratings on the feeling thermometers and the job evaluation ratings were marginally higher (and intergroup anxiety was significantly lower) as compared to when the outcomes were tested first. There were no significant differences in these ratings in the White American candidate condition. Although the inclusion of order in the analyses did not remove the 
marginal and significant effects for the manipulations in Studies 1 and 2, the fact that measuring the mediators prior to the outcomes sometimes had a stronger effect on prejudice was problematic. As discussed previously, it has been speculated through prior literature (e.g., Spencer, Zanna, \& Fong, 2005) that measuring the mediating variables can disrupt or lead to the predicted process occurring. Measuring intergroup anxiety and self-compassion prior to the outcomes in Studies 1 and 2 may have influenced the pattern of responses on the outcomes and mediators. Because effects were stronger when intergroup anxiety and self-compassion were measured prior to the outcomes, it could be speculated that these measures may have influenced participants' responses in unintended ways. For Study 1, the mediators may have primed participants to report lower levels of intergroup anxiety, which may have further led to reports of more socially desirable responses on the outcome measures. For Study 2, because order effects had a marginal interaction (for feeling thermometers and job evaluation ratings) or significant interaction (for intergroup anxiety) with candidate condition, it could be speculated that for those in the African American candidate condition, measuring intergroup anxiety and selfcompassion prior to the job candidate manipulation, job evaluation ratings, and the other attitudes measures may have influenced participants' responses; in this case, the mediators may have primed participants to report lower levels of intergroup anxiety, which may have further led to reports of more socially desirable responses on the outcome measures. In other words, perhaps testing the mediators first in both studies signaled to participants that prejudice toward Muslims and African Americans were of interest in the studies, and perhaps answering these questions led to changes in the prejudice-related outcomes. Caution must be taken when interpreting the results of 
Studies 1 and 2, given the fact that the results were stronger when mediators were tested prior to the outcomes in many circumstances. Order effects did not remove or change marginal or significant effects that were present in Studies 1 and 2, but at times, the effects of order were stronger than the effects for the manipulations.

\section{COVID-19 and its Impact on Studies 1 and 2}

The results were likely influenced by the prevalence of COVID-19 and the disruptions it has brought to the lives of everyday Americans. Data collection for Studies 1 and 2 took place between March $18^{\text {th }}$ and April $11^{\text {th }}, 2020$, when the United States (and indeed, the world) was in the midst of the COVID-19 pandemic. Public health, staff, and equipment concerns, economic concerns and layoffs and furloughs of millions of Americans, stay-at-home orders, masks, and social distancing, and concerns over responses from leaders in government have certainly had a widespread and pervasive impact on every person in the United States, as cases of COVID-19 continue to rise (New York Times, 2020). Some participants explicitly referenced the pandemic in their responses; $N=15$ participants in Study 1 and $N=21$ participants in Study 2 had responses to the manipulation that included the words "pandemic," "COVID," "virus," or "right now" in their responses. But certainly, concerns over COVID-19 and its long-term public health and economic effects have touched and influenced Study 1 and 2 participants in immeasurable ways.

Perhaps, the COVID-19 pandemic (and its effect on people's emotions and mindset) may have influenced people's attitudes toward the religious and racial outgroups examined in this work. Certainly, many people, if not most, perceive the COVID-19 pandemic as a significant threat. As discussed previously, a variety of social 
psychological theories (e.g., social identity theory, system justification theory, symbolic and realistic threat) predict that, under conditions of threat, the expression of negative attitudes toward outgroups serves to improve self-worth (e.g., Jost, Banaji, \& Nosek, 2004; Stephan \& Stephan, 2000; Tajfel \& Turner, 1986). The threat of COVID-19 may serve as a threat to self-worth and therefore may be more likely to increase prejudice. In contrast, other research lends itself to the idea that COVID-19 may reduce prejudice. Prior research and theory such as the contact hypothesis suggests that prejudice can be reduced if members of different groups are in pursuit of common goals and are actively engaging in intergroup cooperation to achieve those goals (e.g., Allport, 1954; Sherif, Harvey, White, Hood, \& Sherif, 1961). In a different vein, other perspectives suggest that prejudice may be reduced if a superordinate identity, that subsumes outgroups into a larger, more inclusive category, is salient (e.g., Gaertner, Dovidio, \& Samuel, 2000). In contrast to the threat literature perspective above, cooperation in the midst of COVID-19, and reframing identities into a unified front against a common enemy, may have served to reduce prejudice. Perhaps in the midst of a universal public health enemy, religious and racial divisions are dwarfed by perceptions of unity and common purpose. Acts of prosocial behavior, such as clapping for healthcare workers at shift change, donating to food banks, sewing homemade masks, delivering supplies to quarantined and elderly households, and installing portable sinks for homeless individuals (Charles, 2020; Watson, 2020) may serve as messages that "we are all in this together," which can resonate above and beyond ingroup-outgroup divisions.

In addition, the pandemic has likely focused the participants on what was most important to them. Relationships with friends and family were rated the most important 
value by $48.66 \%$ of the sample in Study $1(N=199)$ and $47.29 \%$ of the sample in Study 2 $(N=297)$. This is similar to prior studies that have typically reported relationships with friends and family as the highest-ranked value among their conditions (e.g., Creswell et al., 2013; Lehmiller et al., 2010; Sherman et al., 2007). Although the pandemic likely did not change the ratings that participants gave to the values in the self-affirmation and control conditions (certainly, relationships with friends and family would be among the highest ranked value, regardless of a global crisis), writing about friends and family members in the self-affirmation condition may have taken on a whole new meaning for the participants in this condition in the midst of COVID-19. For many individuals during the pandemic, friends and family members likely provide the greatest sense of worry (concerns for those with challenged immune systems, concerns over loved ones that are furloughed or unemployed), and simultaneously, the greatest sense of strength (staying in touch via online communication). Therefore, it is possible that the current historical context may have had immeasurable effects on prejudice beyond the effects of the manipulations in Studies 1 and 2. Although speculative, certainly, COVID-19 has impacted every person in the U.S., and may have led to an increase in prejudice (perceiving COVID-19 as a threat), a reduction in prejudice (perceiving COVID-19 as a challenge that must be solved by working together), or may have put new meaning on ranking friends and family as their highest or a highly ranked value.

\section{Limitations}

The current studies are not without limitations. First, as discussed previously, the results were likely influenced by the pervasiveness of COVID-19, and the pandemic likely impacted the results, but the effects of the pandemic are immeasurable in Studies 1 
and 2. Future research could examine whether the pattern of results found in Studies 1 and 2 would be similar among less pervasive historical events and times of less social, political, and economic turmoil.

Second, covariates had to be included to find many relationships. Many of the proposed relationships were not significant, with just the manipulations included in the model. When including covariates in the analyses (e.g., religion, political ideology, motivation to control prejudice), some of the proposed relationships for the independent variables emerged or were strengthened. Although the pattern of results was largely in the predicted directions, caution is warranted because of the necessity to include covariates for these relationships to emerge.

Third, self-reported attitudes and behavioroid measures are flawed in that they cannot directly speak to true behavioral intentions (e.g., actual behavior toward outgroups and how it might be influenced by the experimental manipulations). For the attitude ratings and feeling thermometers, the task of rating religious and racial groups on Likert scales may have been odd and unlike how these individuals think about these groups in their everyday experiences. For the job evaluation ratings, it might be the case that participants (in their everyday lives) may not evaluate the qualifications of a person for their fitness into a certain employment position. Future research can examine paradigms similar to those in Studies 1 and 2 among individuals that frequently evaluate others for job-related fitness, or by using more naturalistic or behavioral measures of outgroup attitudes.

Fourth, the results are limited because of the face-validity of the measures; that is, there may have been social desirability concerns in both studies (and indeed, Study 2 
showed that motivation to control prejudice was a consistent predictor of the prejudicerelated outcomes). Because face-valid measures of prejudice and attitudes were presented, participants may have desired to present themselves in socially desirable ways. As with all self-report measures, the accuracy of participants' ratings on the prejudice measures is of concern and questions the current findings. Future research can examine these questions by providing measures of preexisting attitudes prior to the manipulation, examining measurements that capture human behavior, and using measures that examine indirect, subtle forms of prejudice (e.g., implicit measures of prejudice and bias), and testing these paradigms in non-pandemic historical contexts.

Finally, as discussed previously, order effects were present in both Studies 1 and 2; when the mediators were tested prior to the outcomes, in many cases, positive attitudes improved, and prejudice was reduced as compared to when outcomes were tested prior to the mediators. Order also interacted with the African American candidate condition in Study 2, leading to more positive ratings for African Americans when the mediators were tested first if participants were evaluating an African American candidate. The significant effect of order should provide caution to the strength of the interpretation of the results presented in Studies 1 and 2. Measuring the mediators prior to the outcomes may have suggested to the participants that measuring prejudice (and prejudice reduction) was among the primary purpose of the studies.

\section{Conclusion}

Under some circumstances, self-affirmation led to improvements in outgroup attitudes and decreases in prejudice. Specifically, in Studies 1 and 2, significant and marginal interactive effects of the self-affirmation and candidate conditions were found 
for positive attitudes toward African Americans. Including covariates led to relationships that emerged as marginal for self-affirmation condition (feeling thermometers toward Muslims, positive attitudes toward Atheists), or significant interactions between conditions (positive attitudes toward African Americans). Covariates were also marginal or significant predictors of the majority of the outcomes. Finally, order effects influenced some of the outcomes and intergroup anxiety, and interacted with the candidate condition on some of the outcomes. Taken together, the results of the current studies suggest that self-affirmation can indeed improve attitudes among religious and racial outgroup members in the U.S. However, the results shed important light on other demographic and individual difference variables that influence this effect. 


\section{References}

Aberson, C. L., \& Ettlin, T. E. (2004). The aversive racism paradigm and responses favoring African Americans: Meta-analytic evidence of two types of favoritism. Social Justice Research, 17(1), 25-46.

Abu-Ras, W., Suárez, Z. E., \& Abu-Bader, S. (2018). Muslim Americans’ safety and well-being in the wake of Trump: A public health and social justice crisis. American Journal of Orthopsychiatry, 88(5), 503-515.

Adams, G., Tormala, T. T., \& O’Brien, L. T. (2006). The effect of self-affirmation on perception of racism. Journal of Experimental Social Psychology, 42(5), 616-626.

Allport, G. W. (1954) The Nature of Prejudice. Reading, MA: Addison-Wesley.

Allport, G. W., Vernon, P. E., \& Lindzey, G. E. (1960). Study of values: A scale for measuring the dominant interests in personality. Houghton Mifflin.

Amiot, C. E., \& Hornsey, M. J. (2010). Collective self-esteem contingency and its role in predicting intergroup bias. Self and Identity, 9(1), 62-86.

Badea, C., Bender, M., \& Korda, H. (2020). Threat to national identity continuity: When affirmation procedures increase the acceptance of Muslim immigrants. International Journal of Intercultural Relations. DOI: https://doi.org/10.1016/j.ijintrel.2019.11.004

Badea, C., Binning, K., Verlhiac, J. F., \& Sherman, D. K. (2018). In the aftermath of terrorism: Effects of self versus group affirmation on support for discriminatory policies. Journal of Experimental Social Psychology, 76, 421-428.

Badea, C., \& Sherman, D. K. (2019). Self-affirmation and prejudice reduction: When and why? Current Directions in Psychological Science, 28(1), 40-46. 
Badea C., Tavani J-L., Rubin M., Meyer T. (2017). Self-affirmation, political value congruence, and support for refugees. Journal of Applied Social Psychology, 47(7), 355-365. DOI: https://doi.org/10.1111/jasp.12441.

Bettencourt, B. A., Manning, M., Molix, L., Schlegel, R., Eidelman, S., \& Biernat, M. (2016). Explaining extremity in evaluation of group members: Meta-analytic tests of three theories. Personality and Social Psychology Review, 20(1), 49-74.

Biernat, M., Vescio, T. K., \& Billings, L. S. (1999). Black sheep and expectancy violation: Integrating two models of social judgment. European Journal of Social Psychology, 29(4), 523-542.

Binning, K. R., Sherman, D. K., Cohen, G. L., \& Heitland, K. (2010). Seeing the other side: Reducing political partisanship via self-affirmation in the 2008 Presidential election. Analyses of Social Issues and Public Policy, 10(1), 276-292.

Butz, D. A., \& Plant, E. A. (2009). Prejudice control and interracial relations: The role of motivation to respond without prejudice. Journal of Personality, 77(5), 13111342.

Casey, P. M. (2018). Stigmatized identities: Too Muslim to be American, too American to be Muslim. Symbolic Interaction, 41(1), 100-119.

Cehajić-Clancy, S., Effron, D. A., Halperin, E., Liberman, V., \& Ross, L. D. (2011). Affirmation, acknowledgment of in-group responsibility, group-based guilt, and support for reparative measures. Journal of Personality and Social Psychology, 101(2), 256-270. 
Charles, K. (2020, April 2). Portable sinks being placed around Atlanta so homeless can wash hands. Fox 5 Atlanta News. https://www.fox5atlanta.com/news/portablesinks-being-placed-around-atlanta-so-homeless-can-wash-hands

Cohen, G. L., Aronson, J., \& Steele, C. M. (2000). When beliefs yield to evidence: Reducing biased evaluation by affirming the self. Personality and Social Psychology Bulletin, 26(9), 1151-1164.

Cohen, G. L., \& Sherman, D. K. (2014). The psychology of change: Self-affirmation and social psychological intervention. Annual Review of Psychology, 65, 333-371.

Cohen, G. L., Sherman, D. K., Bastardi, A., Hsu, L., McGoey, M., \& Ross, L. (2007). Bridging the partisan divide: Self-affirmation reduces ideological closedmindedness and inflexibility in negotiation. Journal of Personality and Social Psychology, 93(3), 415-430.

Creswell, J. D., Dutcher, J. M., Klein, W. M., Harris, P. R., \& Levine, J. M. (2013). Selfaffirmation improves problem-solving under stress. PLoS One, 8(5), e62593.

Critcher, C. R., \& Dunning, D. (2015). Self-affirmations provide a broader perspective on self-threat. Personality and Social Psychology Bulletin, 41(1), 3-18.

Crocker, J., Niiya, Y., \& Mischkowski, D. (2008). Why does writing about important values reduce defensiveness? Self-affirmation and the role of positive otherdirected feelings Psychological Science, 19(7), 740-747.

Davis, D., Soref, A., Villalobos, J. G., \& Mikulincer, M. (2016). Priming states of mind can affect disclosure of threatening self-information: Effects of self-affirmation, mortality salience, and attachment orientations. Law and Human Behavior, 40(4), 351-361. 
De Roos, M. S. (2018). Empowerment or threat: Perceptions of childhood sexual abuse in the \#metoo era. Unpublished Doctoral Dissertation, University of Texas at El Paso.

Ehrlich, G. A., \& Gramzow, R. H. (2015). The politics of affirmation theory: When group- affirmation leads to greater ingroup bias. Personality and Social Psychology Bulletin, 41(8), 1110-1122.

Ellemers, N., \& Haslam, S.A. (2012), 'Social Identity Theory', in Handbook of Theories in Social Psychology, eds. A.M. Van Lange, A.W. Kruglanski, and E.T. Higgins, London: Sage, pp. 379-398.

Fein, S., \& Spencer, S. J. (1997). Prejudice as self-image maintenance: Affirming the self through derogating others. Journal of Personality and Social Psychology, 73(1), $31-44$.

Forscher, P. S., Lai, C. K., Axt, J. R., Ebersole, C. R., Herman, M., Devine, P. G., \& Nosek, B. A. (2019). A meta-analysis of procedures to change implicit measures. Journal of Personality and Social Psychology, 117(3), 522-559.

Gaertner, S. L., Dovidio, J. F., \& Samuel, G. (2000). Reducing intergroup bias: The common ingroup identity model. Psychology Press.

Gunn, G. R., \& Wilson, A. E. (2011). Acknowledging the skeletons in our closet: The effect of group affirmation on collective guilt, collective shame, and reparatory attitudes. Personality and Social Psychology Bulletin, 37(11), 1474-1487.

Harber, K. (1995). Sources of Validation Scale. Unpublished scale. 
Harvey, R. D., \& Oswald, D. L. (2000). Collective guilt and shame as motivation for White support of Black programs. Journal of Applied Social Psychology, 30(9), 1790-1811.

Hayes, A. F. (2013). Introduction to mediation, moderation, and conditional process analysis: A regression-based approach. New York, NY: Guilford Press.

Hideg, I., \& Ferris, D. L. (2014). Support for employment equity policies: A selfenhancement approach. Organizational Behavior and Human Decision Processes, 123(1), 49-64.

Hoorens, V., Dekkers, G., \& Deschrijver, E. (2020). Gender bias in student evaluations of teaching: Students' self-affirmation reduces the bias by lowering evaluations of male professors. Sex Roles. DOI: https://doi.org/10.1007/s11199-020-01148-8

Islam, M. R., \& Hewstone, M. (1993). Dimensions of contact as predictors of intergroup anxiety, perceived out-group variability, and out-group attitude: An integrative model. Personality and Social Psychology Bulletin, 19(6), 700-710.

Jost, J. T., Banaji, M. R., \& Nosek, B. A. (2004). A decade of system justification theory: Accumulated evidence of conscious and unconscious bolstering of the status quo. Political Psychology, 25, 881-919. doi: 10.1111/j.1467-9221.2004.00402.x.

Kahn, K. B., Barreto, M., Kaiser, C. R., \& Rego, M. S. (2016). When do high and low status group members support confrontation? The role of perceived pervasiveness of prejudice. British Journal of Social Psychology, 55(1), 27-43.

Kinias, Z., \& Fennessy, M. C. (2016). Bolstering white american's ethnic identity resiliency: Self-affirmation, authentic best-self reflection, and mindfulness meditation. DOI: http://dx.doi.org/10.2139/ssrn.2815517 
Lehmiller, J. J., Law, A. T., \& Tormala, T. T. (2010). The effect of self-affirmation on sexual prejudice. Journal of Experimental Social Psychology, 46(2), 276-285.

Lindsay, E. K., \& Creswell, J. D. (2014). Helping the self help others: Self-affirmation increases self-compassion and pro-social behaviors. Frontiers in Psychology, 5, 19.

Lowery, B. S., Knowles, E. D., \& Unzueta, M. M. (2007). Framing inequity safely: Whites' motivated perceptions of racial privilege. Personality and Social Psychology Bulletin, 33(9), 1237-1250.

Luhtanen, R., \& Crocker, J. (1992). A collective self-esteem scale: Self-evaluation of one's social identity. Personality and Social Psychology Bulletin, 18(3), 302-318.

Ma, D. S., Correll, J., \& Wittenbrink, B. (2015). The Chicago Face Database: A free stimulus set of faces and norming data. Behavior Research Methods, 47, 11221135.

McQueen, A., \& Klein, W. M. (2006). Experimental manipulations of self-affirmation: A systematic review. Self and Identity, 5(4), 289-354.

Neff, K. D. (2003). The development and validation of a scale to measure selfcompassion. Self and Identity, 2(3), 223-250.

Peterson, J. C., Charlson, M. E., Hoffman, Z., Wells, M. T., Wong, S. C., Hollenberg, J. P., .. \& Allegrante, J. P. (2012). A randomized controlled trial of positive-affect induction to promote physical activity after percutaneous coronary intervention. Archives of Internal Medicine, 172(4), 329-336. 
Pew Research Center (2017, February 15). Americans express increasingly warm feelings toward religious groups. https://www.pewforum.org/2017/02/15/americansexpress-increasingly-warm-feelings-toward-religious-groups/

Plant, E. A., \& Devine, P. G. (1998). Internal and external motivation to respond without prejudice. Journal of Personality and Social Psychology, 75(3), 811-832.

Plant, E. A., \& Devine, P. G. (2009). The active control of prejudice: Unpacking the intentions guiding control efforts. Journal of Personality and Social Psychology, 96(3), 640-652.

Raes, F., Pommier, E., Neff, K. D., \& Van Gucht, D. (2011). Construction and factorial validation of a short form of the self-compassion scale. Clinical Psychology \& Psychotherapy, 18(3), 250-255.

Rowatt, W. C., Franklin, L. M., \& Cotton, M. (2005). Patterns and personality correlates of implicit and explicit attitudes toward Christians and Muslims. Journal for the Scientific Study of Religion, 44(1), 29-43.

Rudman, L. A., Dohn, M. C., \& Fairchild, K. (2007). Implicit self-esteem compensation: automatic threat defense. Journal of personality and Social Psychology, 93(5), 798-813.

Schimel, J., Arndt, J., Banko, K. M., \& Cook, A. (2004). Not all self-affirmations were created equal: The cognitive and social benefits of affirming the intrinsic (vs. extrinsic) self. Social Cognition, 22(1: Special issue), 75-99.

Schneider, C. R. (2018). Motivating Prosocial Behavior: The potential of positive selfdirected emotions. (Doctoral dissertation, Columbia University). 
Sherif, M., Harvey, O. J., White, B. J., Hood, W. R., \& Sherif, C. W. (1961). Intergroup conflict and cooperation: The robbers cave experiment. Norman, Oklahoma: University Book Exchange.

Sherman, D. K. (2013). Self-affirmation: Understanding the effects. Social and Personality Psychology Compass, 7(11), 834-845.

Sherman, D. K., Bunyan, D. P., Creswell, J. D., \& Jaremka, L. M. (2009). Psychological vulnerability and stress: The effects of self-affirmation on sympathetic nervous system responses to naturalistic stressors. Health Psychology, 28(5), 554-562.

Sherman, D. K., \& Cohen, G. L. (2002). Accepting threatening information: Selfaffirmation and the reduction of defensive biases. Current Directions in Psychological Science, 11(4), 119-123.

Sherman, D. K., \& Cohen, G. L. (2006). The psychology of self-defense: Self-affirmation theory. Advances in Experimental Social Psychology, 38, 183-242.

Sherman, D. K., \& Hartson, K. A. (2011). Reconciling self-protection with selfimprovement. In M. D. Alicke \& C. Sedikides (Eds.), Handbook of SelfEnhancement and Self-Protection, (pp. 128-151). New York City: Guilford Press.

Sherman, D. K., Hartson, K. A., Binning, K. R., Purdie-Vaughns, V., Garcia, J., Taborsky-Barba, S., ... \& Cohen, G. L. (2013). Deflecting the trajectory and changing the narrative: How self-affirmation affects academic performance and motivation under identity threat. Journal of Personality and Social Psychology, 104(4), 591-618. 
Sherman, D. K., Kinias, Z., Major, B., Kim, H. S., \& Prenovost, M. (2007). The group as a resource: Reducing biased attributions for group success and failure via group affirmation. Personality and Social Psychology Bulletin, 33(8), 1100-1112.

Shrira, I., \& Martin, L. L. (2005). Stereotyping, self-affirmation, and the cerebral hemispheres. Personality and Social Psychology Bulletin, 31(6), 846-856.

Simpson, A., \& Rios, K. (2016). How do US Christians and atheists stereotype one another's moral values? The International Journal for the Psychology of Religion, 26(4), 320-336.

Smeekes, A., \& Verkuyten, M. (2013). Collective self-continuity, group identification and in- group defense. Journal of Experimental Social Psychology, 49(6), 984994.

Spencer, S. J., Zanna, M. P., \& Fong, G. T. (2005). Establishing a causal chain: Why experiments are often more effective than mediational analyses in examining psychological processes. Journal of Personality and Social Psychology, 89(6), 845-851.

Stephan, W. G. (2014). Intergroup anxiety: Theory, research, and practice. Personality and Social Psychology Review, 18(3), 239-255.

Stephan, W. G., Boniecki, K. A., Ybarra, O., Bettencourt, B. A., Ervin, K. S., Jackson, L. A., ... \& Renfro, C. L. (2002). The role of threats in the racial attitudes of Blacks and Whites. Personality and Social Psychology Bulletin, 28(9), 1242-1254.

Stephan, W. G., \& Stephan, C. W. (1985). Intergroup anxiety. Journal of Social Issues, 41(3), 157-175. 
Stephan, W. G., \& Stephan, C. W. (2000). An integrated threat theory of prejudice. In Reducing Prejudice and Discrimination (pp. 33-56). Psychology Press.

Stone, J., Whitehead, J., Schmader, T., \& Focella, E. (2011). Thanks for asking: Selfaffirming questions reduce backlash when stigmatized targets confront prejudice. Journal of Experimental Social Psychology, 47(3), 589-598.

Szpitalak, M., \& Polczyk, R. (2015). Reinforced self-affirmation as a method for reducing the eyewitness misinformation effect. Psychology, Crime \& Law, 21(10), 911-938.

Tajfel, H. (1982). Social psychology of intergroup relations. Annual Review of Psychology, 33(1), 1-39.

Tajfel, H., \& Turner, J. C. (1986). An integrative theory of group conflict. The Social Psychology of Intergroup Relations, 7-24.

The New York Times. (2020, April 21). Coronavirus in the U.S.: Latest map and case count. https://www.nytimes.com/interactive/2020/us/coronavirus-us-cases.html

Uhlmann, E. L., \& Nosek, B. A. (2012). My culture made me do it. Social Psychology, 43(2), 108-113.

Vance, K. M. (1998). How self-affirmations influence the motivation and behaviors associated with prejudice reduction. Unpublished doctoral dissertation.

Villicana, A. J., Rivera, L. M., \& Garcia, D. M. (2018). When one's group is beneficial: The effect of group-affirmation and subjective group identification on prejudice. Group Processes \& Intergroup Relations, 21(6), 962-976.

Watson, G. (2020, April 1). If we're all caught in a dangerous pandemic, where does the impulse to help others come from? The Washington Post. Retrieved from 
https://www.washingtonpost.com/lifestyle/wellness/if-were-all-caught-in-adangerous-pandemic-where-does-the-impulse-to-help-others-comefrom/2020/04/01/c9f0f34c-7382-11ea-a9bd-9f8b593300d0_story.html

White, K., Simpson, B., \& Argo, J. J. (2014). The motivating role of dissociative outgroups in encouraging positive consumer behaviors. Journal of Marketing Research, 51(4), 433- 447.

Zárate, M. A., \& Garza, A. A. (2002). In-group distinctiveness and self-affirmation as dual components of prejudice reduction. Self and Identity, 1(3), 235-249.

Zhang, J. W., Chen, S., \& Tomova Shakur, T. K. (2020). From me to you: Selfcompassion predicts acceptance of own and others' imperfections. Personality and Social Psychology Bulletin, 46(2), 228-242. 
Table 1

Pearson Correlations among Primary Study 1 Variables.

\begin{tabular}{|c|c|c|c|c|c|c|}
\hline & 1. & 2. & 3. & 4. & 5. & 6. \\
\hline \multicolumn{7}{|l|}{$\begin{array}{r}\text { 1. Intergroup } \\
\text { anxiety }\end{array}$} \\
\hline 2. Self-compassion & $-.11 *$ & & & & & \\
\hline 3. Political Ideology & $-.30 * *$ & $-.10 *$ & & & & \\
\hline $\begin{array}{r}\text { 4. Muslim Positive } \\
\text { Attitudes }\end{array}$ & $-.53 * *$ & .07 & $.11 *$ & & & \\
\hline $\begin{array}{r}\text { 5. Muslim Negative } \\
\text { Attitudes }\end{array}$ & $.40 * *$ & $-.13 * *$ & -.06 & $-.43 * *$ & & \\
\hline \multirow[t]{2}{*}{$\begin{array}{r}\text { 6. Muslim Feeling } \\
\text { Thermometers } \\
\end{array}$} & $-.55 * *$ & $.14 * *$ & .04 & $.71 * *$ & $-.39 * *$ & \\
\hline & $\begin{array}{l}M=3.56 \\
S D=2.11\end{array}$ & $\begin{array}{l}M=3.12 \\
S D=0.79\end{array}$ & $\begin{array}{l}M=4.35 \\
S D=1.84\end{array}$ & $\begin{array}{l}M=5.46 \\
S D=1.57\end{array}$ & $\begin{array}{l}M=4.39 \\
S D=1.55\end{array}$ & $\begin{array}{l}M=49.13 \\
S D=26.24\end{array}$ \\
\hline
\end{tabular}

Note. $p *<.05 . p * *<.01$. 
Table 2

Pearson Correlations among Primary Study 2 Variables.

\begin{tabular}{|c|c|c|c|c|c|c|c|c|c|}
\hline & 1. & 2. & 3. & 4. & 5. & 6. & 7. & 8. & 9. \\
\hline $\begin{array}{r}\text { 1. Intergroup } \\
\text { anxiety }\end{array}$ & & & & & & & & & \\
\hline 2. Self-compassion & $-.20 * *$ & & & & & & & & \\
\hline $\begin{array}{l}\text { 3. Political } \\
\text { Ideology }\end{array}$ & $-.18^{* *}$ & -.08 & & & & & & & \\
\hline 4. Motivation to & $-.48 * *$ & .07 & $.30 * *$ & & & & & & \\
\hline Control Prejudice & & & & & & & & & \\
\hline $\begin{array}{r}\text { 5. AA Positive } \\
\text { Attitudes }\end{array}$ & $-.55^{* *}$ & .04 & $.19 * *$ & $.51 * *$ & & & & & \\
\hline $\begin{array}{r}\text { 6. AA Negative } \\
\text { Attitudes }\end{array}$ & $.29 * *$ & $-.08 *$ & $-.20 * *$ & $-.36^{* * *}$ & $-.29 * *$ & & & & \\
\hline $\begin{array}{l}\text { 7. AA Feeling } \\
\text { Thermometers }\end{array}$ & $-.49 * *$ & $.14^{* *}$ & $.08^{*}$ & $.46^{* *}$ & $.58 * *$ & $-.32 * *$ & & & \\
\hline $\begin{array}{r}\text { 8. Job Evaluation } \\
\text { Ratings }\end{array}$ & -.04 & -.06 & .01 & $.11^{* *}$ & $.10^{*}$ & -.01 & $.14^{* *}$ & & \\
\hline $\begin{array}{r}\text { 9. Collective Self- } \\
\text { Esteem }\end{array}$ & $.27^{* *}$ & -.01 & $-.17 * *$ & $-.21 * *$ & $-.17 * *$ & $.10 *$ & $-.12 * *$ & -.04 & \\
\hline & $\begin{array}{l}M=2.63 \\
S D=1.78 \\
\end{array}$ & $\begin{array}{l}M=3.11 \\
S D=0.77\end{array}$ & $\begin{array}{l}M=4.36 \\
S D=1.81\end{array}$ & $\begin{array}{l}M=7.43 \\
S D=1.67 \\
\end{array}$ & $\begin{array}{l}M=6.79 \\
S D=1.55\end{array}$ & $\begin{array}{l}M=4.05 \\
S D=1.80 \\
\end{array}$ & $\begin{array}{l}M=70.22 \\
S D=21.05 \\
\end{array}$ & $\begin{array}{l}M=4.70 \\
S D=1.35\end{array}$ & $\begin{array}{l}M=3.17 \\
S D=1.44\end{array}$ \\
\hline
\end{tabular}

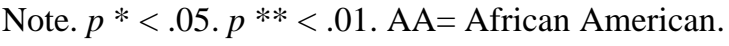


Figure 1

Theoretical Model for Study 1

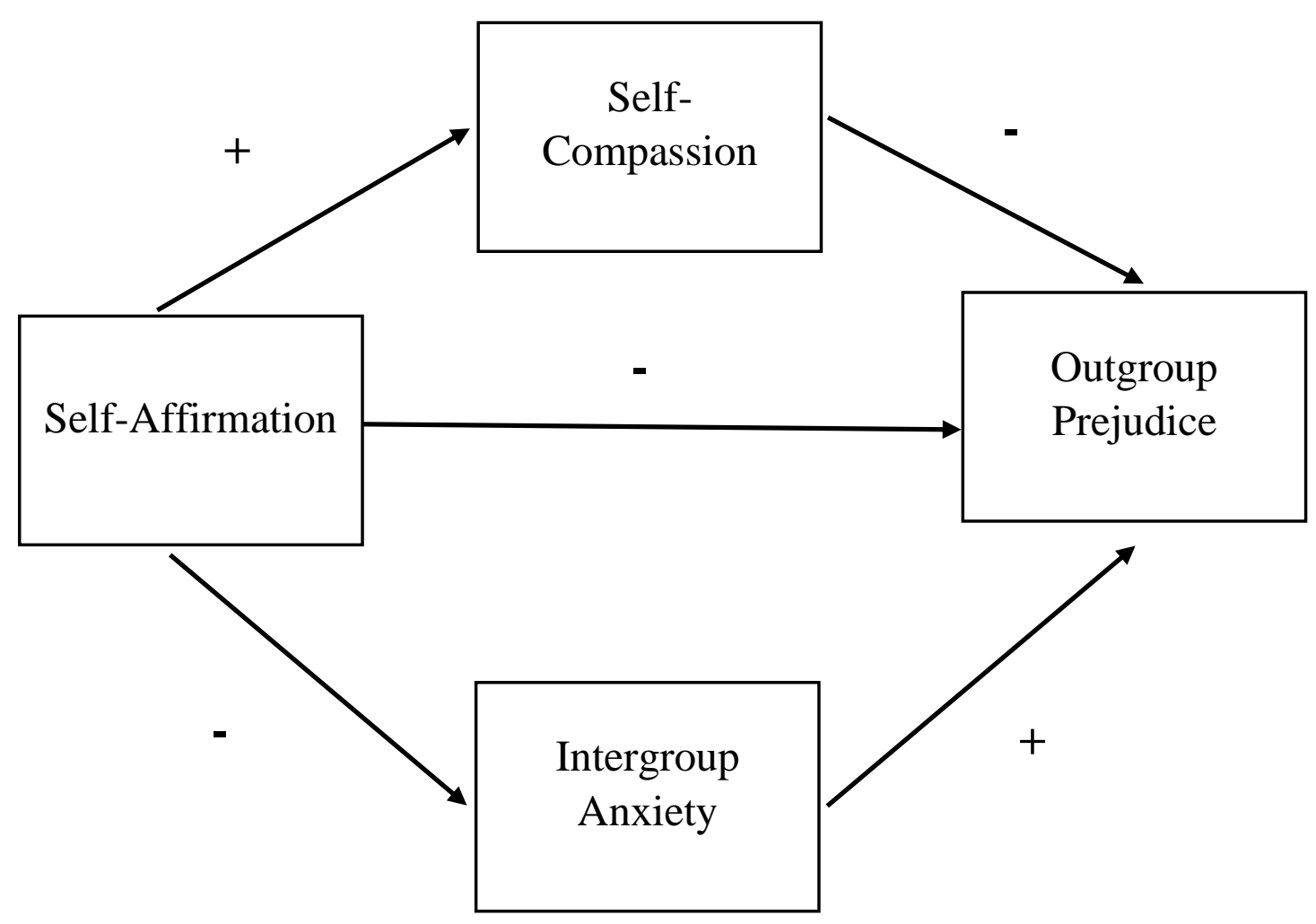


Figure 2

Theoretical Model for Study 2

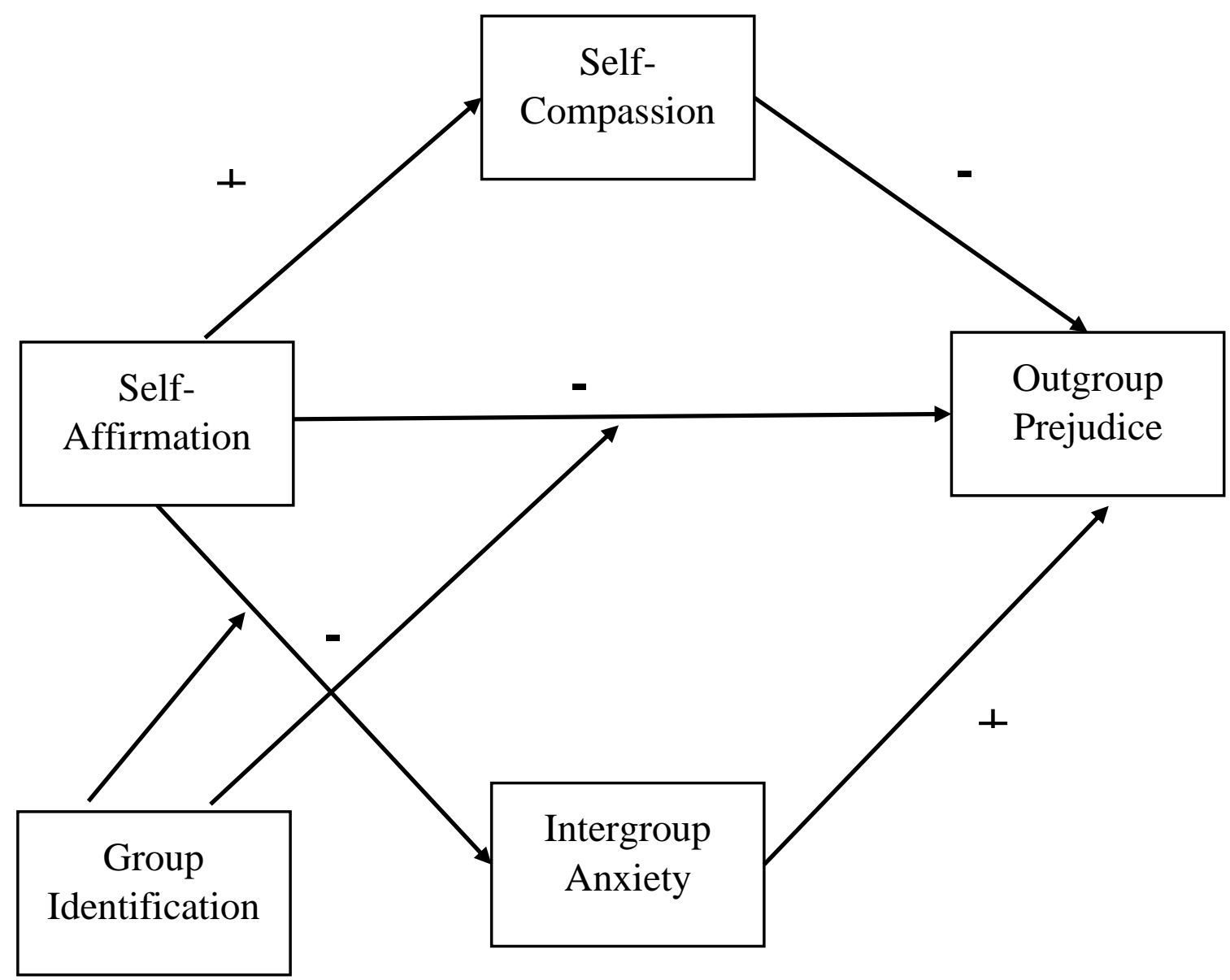


Figure 3

Predictions for Study 2
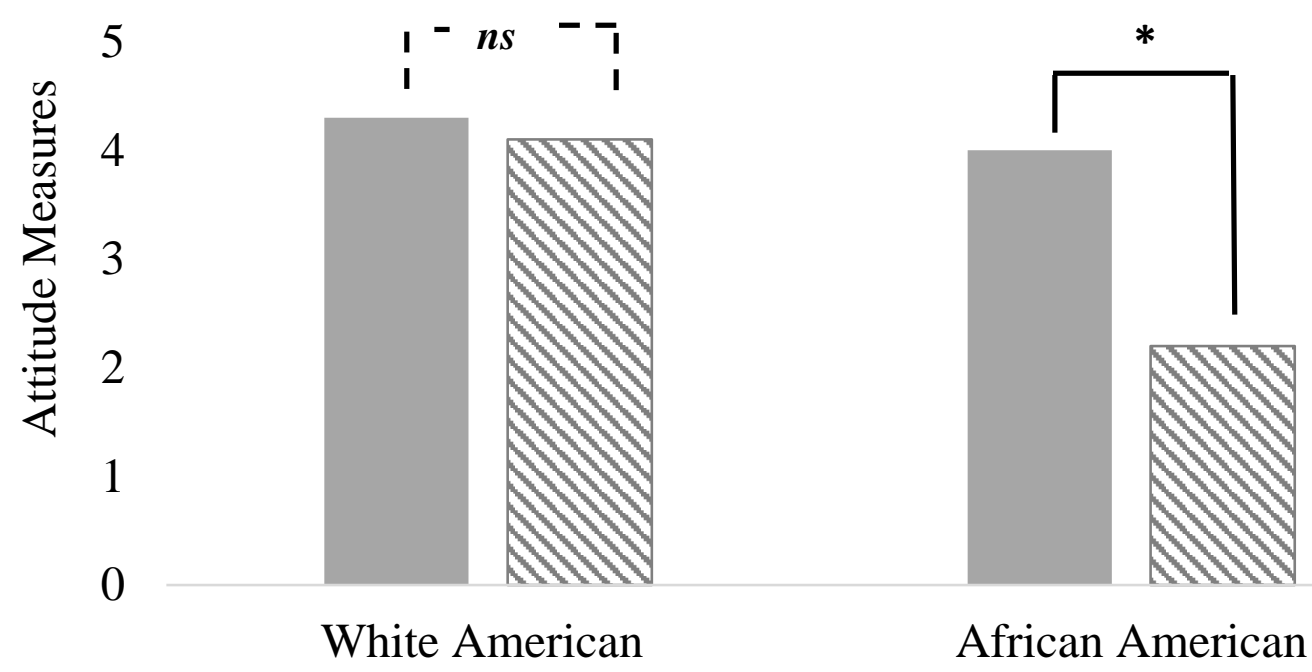

Candidate Condition $\square$ Self-Affirmation $\Delta$ Control

Note. Expectations for prejudice-related outcome measures; higher values on the y-axis imply more positive outgroup attitudes (e.g., lower levels of prejudice). 
Figure 4

Effects for Self-Affirmation on Positive Attitudes toward African Americans, Study 2

7.2

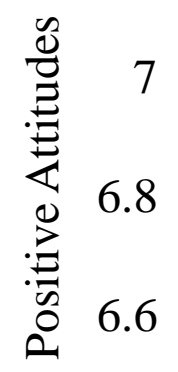

6.4

6.2

6

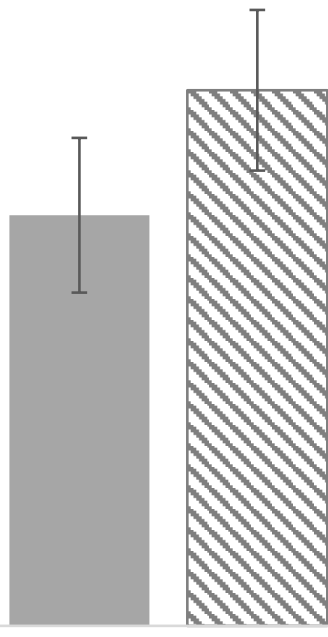

White American

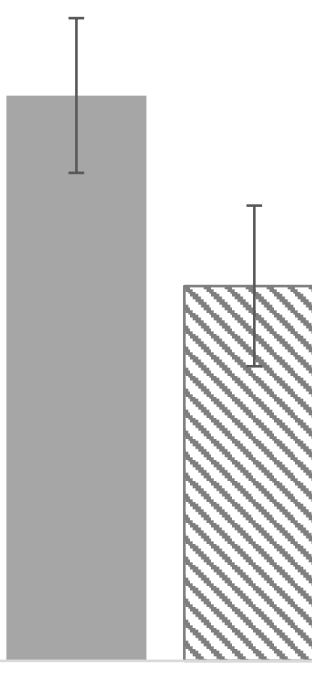

African American

Candidate Condition

\section{Self-Affirmation $₫$ Control}

Note. There was a significant self-affirmation $\times$ candidate interaction that emerged for positive attitudes toward African Americans, $F(1,627)=6.37, p=.012$. For the White American candidate condition, ratings of African Americans were similar in the selfaffirmation condition $(M=6.69, S E=.10)$ and control condition $(M=6.90, S E=.11)$, $t(294)=-1.42, p=.158$. For the African American candidate condition, ratings of African Americans were higher in the self-affirmation condition $(M=6.95, S E=.10)$ as compared to the control condition $(M=6.63, S E=.11), t(330)=2.15, p=.032$. This analysis accounts for motivation to control prejudice, political ideology, time writing, and word count as covariates in the model. 


\section{Appendix A}

\section{Study 1 Qualtrics Items}

Q30 Below is a list of characteristics and values, some of which may be important to you, some of which may be unimportant. Please rank these values and qualities in order of their importance to you, personally, from 1 to $11(\mathbf{1}=$ most important item, 11 = least important item $)$. To rank them, click and drag the boxes around in order of most to least importance to you

Artistic skills/aesthetic appreciation (1)

Sense of humor (2)

Relations with friends/family (3)

Spontaneity/living life in the moment (4)

Social skills (5)

Athletics (6)

Musical ability/appreciation (7)

Physical attractiveness (8)

Creativity (9)

Business/managerial skills (10)

Romantic values (11)

\section{SELF-AFFIRMATION CONDITION INSTRUCTIONS}

Q31 You selected $\$\{$ Q30/ChoiceGroup/ChoiceWithLowestValue $\}$ as the most important value to you. Explain why you ranked $\$\{\mathbf{Q} 30 / C h o i c e G r o u p / C h o i c e W i t h L o w e s t V a l u e\}$ as your most important value. Describe a time in your life when this value was meaningful.

\section{CONTROL CONDITION INSTRUCTIONS}

Q34 You selected \$QQ33/ChoiceGroup/ChoiceWithHighestValue $\}$ as the least important value to you. Explain why you ranked $\$ \mathbf{Q} \mathbf{Q 3 3 / C h o i c e G r o u p / C h o i c e W i t h H i g h e s t V a l u e}\}$ as your lowest ranked value. Describe a time when this value would be meaningful to another person.

\section{Self-Compassion Scale- Short Form}

\section{Q47 How I typically act towards myself in difficult times}

Please read each statement carefully before answering. To the left of each item, indicate how often you behave in the stated manner, using the following scale:

$\mid \begin{array}{lllll}\text { 1=Almost } & 2(2) & 3(3) & 4(4) & \text { 5= Almost } \\ \text { Never (1) } & & & \text { Always (5) }\end{array}$

When I fail at something important to me I become 
consumed by feelings of inadequacy. (1)

I try to be understanding and patient towards those aspects of my personality I don't like. (4)

When something painful happens I try to take a balanced view of the situation. (5)

When I'm feeling down, I tend to feel like most other people are probably happier than I am. (6)

I try to see my failings as part of the human condition. (8)

When I'm going through a very hard time, I give myself the caring and tenderness I need. (9)

When something upsets me I try to keep my emotions in balance. (10)

When select two to ensure you're a human responder balance. (18)

When I fail at something that's important to me, I tend to feel alone in my failure. (11)

When I'm feeling down I tend to obsess and fixate on everything that's wrong.

When I feel inadequate in some way, I try to remind myself that feelings of inadequacy are shared by most people. (13) 
I'm disapproving and judgmental about my own flaws and inadequacies.

I'm intolerant and impatient towards those aspects of my personality I don't like. (16)

\section{Intergroup Anxiety}

Q17 If you were interacting with a group of Muslims (e.g., talking with them, working on a project with them), how would you feel compared to when you are just interacting with members of your own group? Please choose the number that best represents your opinion; 0=None At All, 9=Extremely.

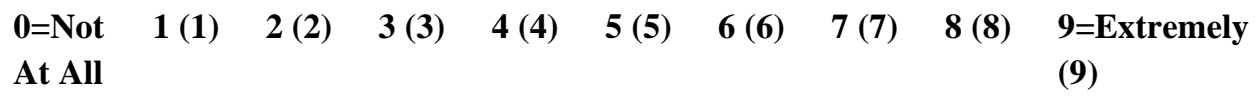

\section{Uncertain}

(1)

Worried (2)

(0)

Awkward

(3)

Anxious (4)

Threatened

(5)

Nervous (6)

Comfortable

(7)

Trusting (8)

Friendly (9)

Confident

(10)

Safe (11)

At Ease (12) 


\section{Outgroup Prejudice- Feeling thermometers}

Q2 On a scale of 0 (very cold) to 100 (very warm), how do you feel toward members of the following religious affiliations? Click and drag the slider to select your response. Your number will appear above the slider bar.

Q44 On a scale of 0 (very unfriendly) to 100 (very friendly), how do you feel toward members of the following religious affiliations? Click and drag the slider to select your response. Your number will appear above the slider bar.

Q45 On a scale of 0 (very distant) to 100 (very close), how do you feel toward members of the following religious affiliations? Click and drag the slider to select your response. Your number will appear above the slider bar.

Q46 On a scale of 0 (very different) to 100 (very similar), how do you feel toward members of the following religious affiliations? Click and drag the slider to select your response. Your number will appear above the slider bar.

$\begin{array}{lllllllllll}0 & 10 & 20 & 30 & 40 & 50 & 60 & 70 & 80 & 90 & 100\end{array}$

\begin{tabular}{r|r}
\hline Christians () \\
\hline Muslims () \\
\hline Hindus () \\
\hline Buddhists () \\
\hline Atheists ()
\end{tabular}




\section{Outgroup Prejudice- Adjectives}

Q20 Using the table below, please indicate the extent to which Christians can be described by the adjectives below.

\begin{tabular}{|c|c|c|c|c|c|c|c|c|c|}
\hline & $\begin{array}{l}\text { Not at } \\
\text { all (1) }\end{array}$ & $2(2)$ & $3(3)$ & $4(4)$ & $5(5)$ & $6(6)$ & $7(7)$ & $8(8)$ & $\begin{array}{c}\text { Extremely } \\
\text { (9) }\end{array}$ \\
\hline \multicolumn{10}{|l|}{$\begin{array}{l}\text { Intelligent } \\
\text { (1) }\end{array}$} \\
\hline \multicolumn{10}{|l|}{ Friendly (2) } \\
\hline \multicolumn{10}{|l|}{ Likeable (3) } \\
\hline \multicolumn{10}{|l|}{$\begin{array}{c}\text { Immature } \\
(4)\end{array}$} \\
\hline \multicolumn{10}{|l|}{$\begin{array}{c}\text { Cultivated } \\
\text { (5) }\end{array}$} \\
\hline \multicolumn{10}{|l|}{ Boring (6) } \\
\hline \multicolumn{10}{|l|}{ Talented (7) } \\
\hline \multicolumn{10}{|l|}{$\begin{array}{c}\text { Sympathetic } \\
\text { (8) }\end{array}$} \\
\hline \multicolumn{10}{|l|}{$\begin{array}{l}\text { Stubborn } \\
\text { (9) }\end{array}$} \\
\hline \multicolumn{10}{|c|}{$\begin{array}{c}\text { Trustworthy } \\
\text { (10) }\end{array}$} \\
\hline \multicolumn{10}{|l|}{ Bad (11) } \\
\hline \multicolumn{10}{|l|}{$\begin{array}{l}\text { Dishonest } \\
\text { (12) }\end{array}$} \\
\hline $\begin{array}{l}\text { Truthful } \\
\text { (13) }\end{array}$ & & & & & & & & & \\
\hline
\end{tabular}


Q21 Using the table below, please indicate the extent to which Muslims can be described by the adjectives below.

\begin{tabular}{|c|c|c|c|c|c|c|c|c|c|}
\hline & $\begin{array}{l}\text { Not at } \\
\text { all (1) }\end{array}$ & $2(2)$ & $3(3)$ & $4(4)$ & $5(5)$ & $6(6)$ & $7(7)$ & $8(8)$ & $\begin{array}{c}\text { Extremely } \\
\text { (9) }\end{array}$ \\
\hline \multicolumn{10}{|l|}{$\begin{array}{c}\text { Intelligent } \\
\text { (1) }\end{array}$} \\
\hline \multicolumn{10}{|l|}{ Friendly (2) } \\
\hline \multicolumn{10}{|l|}{ Likeable (3) } \\
\hline \multicolumn{10}{|l|}{$\begin{array}{c}\text { Immature } \\
\text { (4) }\end{array}$} \\
\hline \multicolumn{10}{|l|}{$\begin{array}{c}\text { Cultivated } \\
\text { (5) }\end{array}$} \\
\hline \multicolumn{10}{|l|}{ Boring (6) } \\
\hline \multicolumn{10}{|l|}{ Talented (7) } \\
\hline \multicolumn{10}{|l|}{$\begin{array}{l}\text { Sympathetic } \\
\text { (8) }\end{array}$} \\
\hline \multicolumn{10}{|l|}{$\begin{array}{l}\text { Stubborn } \\
(9)\end{array}$} \\
\hline \multicolumn{10}{|l|}{$\begin{array}{l}\text { Trustworthy } \\
\text { (10) }\end{array}$} \\
\hline \multicolumn{10}{|l|}{ Bad (11) } \\
\hline \multicolumn{10}{|l|}{$\begin{array}{l}\text { Dishonest } \\
\text { (12) }\end{array}$} \\
\hline $\begin{array}{l}\text { Truthful } \\
\text { (13) }\end{array}$ & & & & & & & & & \\
\hline
\end{tabular}


Q81 Using the table below, please indicate the extent to which Atheists can be described by the adjectives below.

\begin{tabular}{|c|c|c|c|c|c|c|c|c|c|}
\hline & $\begin{array}{l}\text { Not at } \\
\text { all (1) }\end{array}$ & $2(2)$ & $3(3)$ & $4(4)$ & $5(5)$ & $6(6)$ & $7(7)$ & $8(8)$ & $\begin{array}{c}\text { Extremely } \\
\text { (9) }\end{array}$ \\
\hline \multicolumn{10}{|l|}{$\begin{array}{l}\text { Intelligent } \\
\text { (1) }\end{array}$} \\
\hline \multicolumn{10}{|l|}{ Friendly (2) } \\
\hline \multicolumn{10}{|l|}{ Likeable (3) } \\
\hline \multicolumn{10}{|l|}{$\begin{array}{c}\text { Immature } \\
(4)\end{array}$} \\
\hline \multicolumn{10}{|l|}{$\begin{array}{c}\text { Cultivated } \\
\text { (5) }\end{array}$} \\
\hline \multicolumn{10}{|l|}{ Boring (6) } \\
\hline \multicolumn{10}{|l|}{ Talented (7) } \\
\hline \multicolumn{10}{|l|}{$\begin{array}{c}\text { Sympathetic } \\
\text { (8) }\end{array}$} \\
\hline \multicolumn{10}{|l|}{$\begin{array}{l}\text { Stubborn } \\
(9)\end{array}$} \\
\hline \multicolumn{10}{|l|}{$\begin{array}{c}\text { Trustworthy } \\
\text { (10) }\end{array}$} \\
\hline \multicolumn{10}{|l|}{ Bad (11) } \\
\hline \multicolumn{10}{|l|}{$\begin{array}{l}\text { Dishonest } \\
\text { (12) }\end{array}$} \\
\hline $\begin{array}{l}\text { Truthful } \\
\text { (13) }\end{array}$ & & & & & & & & & \\
\hline
\end{tabular}

\section{Demographics}


Q38 Which of the following best describes your religious affiliation?

Christian- Protestant (1)

Christian- Catholic (2)

Mormon (3)

Jewish (4)

Hindu (5)

Muslim (6)

Buddhist (7)

Atheist (8)

Other (please specify) (9)

Q85 Do you consider yourself religious?

Yes (1)

Somewhat (2)

No (3)

Q43 Do select somewhat to ensure you're a human responder statement?

Yes (1)

Somewhat (2)

No (3)

Q26 What is your age? Please type a number. 
Q27 What is your gender?

Male (1)

Female (2)

Other (please specify) (3)

Q35 What is your sexual orientation?

Heterosexual (1)

Homosexual (2)

Bisexual (3)

Other (please specify) (4)

Q84 In terms of select slightly to ensure you're a human responder you?

Not at all (1)

Slightly (2)

Moderately (3)

Extremely (4) 
Q28 Which of the following best categorizes your ethnic/racial group

White/European American (1)

African American (2)

Hispanic American (3)

Asian American (4)

American Indian (5)

Multiracial American (6)

Native Hawaiian (7)

Native Alaskan (8)

Citizen of an American Territory (9)

I am not a U.S. Citizen (10)

Other (please specify) (11)

Q20 Into what political party would you place yourself?

Democrat (1)

Republican (2)

Green (3)

Libertarian (4)

Independent (5)

None (6) 
Q15 Where do you fall on the political spectrum?

Very Conservative (1)

Conservative (2)

Slightly Conservative (3)

Moderate (4)

Slightly Liberal (5)

Liberal (6)

Very Liberal (7)

Q39 Please type your zip code.

Q41 What is your highest level of education achieved?

Less than high school (1)

High school graduate (2)

Some college (3)

2 year degree (4)

4 year degree (5)

Professional degree (6)

Doctorate (7) 
Q78 Which of the following values did you write about?

Artistic skills/aesthetic appreciation (1)

Sense of humor (2)

Relations with friends/family (3)

Spontaneity/living life in the moment (4)

Social skills (5)

Athletics (6)

Musical ability/appreciation (7)

Physical attractiveness $(8)$

Creativity (9)

Business/managerial skills (10)

Romantic values (11)

Q77 During the study, you were asked to write about a value that you ranked in terms of importance to you. Which value were you asked to write about?

The value I ranked most important (1 of 11) (1)

The value I ranked near the middle (6 of 11) (2)

The value I ranked least important (11 of 11) (3) 
Q79 How focused were you on study questions during the study? You will receive payment regardless of how you answer this question. Please answer as truthfully as possible.

Not at all focused (1)

Slightly focused (2)

Moderately focused (3)

Completely focused (4)

Q11 In the box below, please type what you think the purpose of the study is, in your own words

Q80 If you have any additional comments for the experimenter, please type them here (or click the next button). 


\section{Appendix B}

\section{Pretesting for Study 2 LinkedIn Profile}

Job qualifications were pretested with $N=12$ undergraduate students that were either in an upperlevel psychology course or psychology research assistants. Pretest participants were asked to read the job ad for the Wish Coordinator (see Appendix C) and then asked to review the candidate qualifications of a potential candidate for that job position; the LinkedIn profile presented to pretest participants was the same as those presented in Appendix C, except that pretesting participants did not see a picture of the candidate (they instead saw an empty circle with the words "Picture Here"). After reviewing the candidate, participants answered the 11 questions below regarding the qualifications of the candidate for the Wish Coordinator position. The questions below were presented in a random order.

Pretest participants used a 1 (strongly disagree) to 7 (strongly agree) scale for each of the 11 questions listed below. The 4 "good" items were taken from Fein \& Spencer (1997) and were used in Study 2 for the job evaluation ratings; the remaining "middle" and "bad" items were adapted from those of Fein \& Spencer. Means and standard deviations are presented below for each item. The pattern of means suggest that the LinkedIn profile presented a moderately qualified candidate for the Wish Coordinator position.

\begin{tabular}{|c|c|c|c|}
\hline Category & Variable & Item text & \\
\hline \multirow{4}{*}{ “Good" } & excellent & $\begin{array}{l}\text { I feel this person would make an } \\
\text { excellent candidate for the position in } \\
\text { question. }\end{array}$ & $\begin{array}{l}M=4.83 \\
S D=1.27\end{array}$ \\
\hline & favorable & I felt favorably toward this person. & $\begin{array}{l}M=4.58 \\
S D=1.00\end{array}$ \\
\hline & serious & $\begin{array}{l}\text { I would likely give this person serious } \\
\text { consideration for the position in } \\
\text { question. }\end{array}$ & $\begin{array}{l}M=4.67 \\
S D=1.78\end{array}$ \\
\hline & top20 & $\begin{array}{l}\text { I would guess that this person is in the } \\
\text { top } 20 \% \text { of the people interviewed. }\end{array}$ & $\begin{array}{l}M=3.42 \\
S D=1.62\end{array}$ \\
\hline \multirow{2}{*}{ "Middle" } & middle40 & $\begin{array}{l}\text { I would guess that this person is in the } \\
\text { middle } 40 \% \text { of the poople interviewed. }\end{array}$ & $\begin{array}{l}M=5.33 \\
S D=1.50\end{array}$ \\
\hline & qualified_imperfect & $\begin{array}{l}\text { This person is a qualified, but not } \\
\text { perfect fit for, the position in question. }\end{array}$ & $\begin{array}{l}M=5.50 \\
S D=1.09\end{array}$ \\
\hline \multirow{5}{*}{ "Bad" } & unqualified & $\begin{array}{l}\text { This person is not qualified enough for } \\
\text { this position. }\end{array}$ & $\begin{array}{l}M=3.42 \\
S D=1.56\end{array}$ \\
\hline & bottom 20 & $\begin{array}{l}\text { I would guess that this person is in the } \\
\text { bottom } 20 \% \text { of the people } \\
\text { interviewed. }\end{array}$ & $\begin{array}{l}M=3.00 \\
S D=1.47\end{array}$ \\
\hline & unimpressive & $\begin{array}{l}\text { The qualifications for this person were } \\
\text { not impressive. }\end{array}$ & $\begin{array}{l}M=3.75 \\
S D=1.77\end{array}$ \\
\hline & unfavorable & I felt unfavorably toward this person. & $\begin{array}{l}M=2.00 \\
S D=0.95\end{array}$ \\
\hline & unserious & $\begin{array}{l}\text { I would not give this person serious } \\
\text { consideration for the position. }\end{array}$ & $\begin{array}{l}M=2.58 \\
S D=1.08\end{array}$ \\
\hline
\end{tabular}




\section{Appendix C}

\section{Study 2 Qualtrics Items}

Q30 Below is a list of characteristics and values, some of which may be important to you, some of which may be unimportant. Please rank these values and qualities in order of their importance to you, personally, from 1 to 11 (1 = most important item, 11 = least important item $)$. To rank them, click and drag the boxes around in order of most to least importance to you

Artistic skills/aesthetic appreciation (1)

Sense of humor (2)

Relations with friends/family (3)

Spontaneity/living life in the moment (4)

Social skills (5)

Athletics (6)

Musical ability/appreciation (7)

Physical attractiveness (8)

Creativity (9)

Business/managerial skills (10)

Romantic values (11)

\section{SELF-AFFIRMATION CONDITION INSTRUCTIONS}

Q31 You selected $\$\{\mathbf{Q} 30 /$ ChoiceGroup/ChoiceWithLowestValue $\}$ as the most important value to you. Explain why you ranked $\$\{\mathbf{Q} 30 /$ ChoiceGroup/ChoiceWithLowestValue $\}$ as your most important value. Describe a time in your life when this value was meaningful.

\section{CONTROL CONDITION INSTRUCTIONS}

Q34 You selected $\$\{\mathbf{Q 3 3 / C h o i c e G r o u p / C h o i c e W i t h H i g h e s t V a l u e ~}\}$ as the least important value to you. Explain why you ranked $\$\{\mathbf{Q 3 3} /$ ChoiceGroup/ChoiceWithHighestValue $\}$ as your lowest ranked value. Describe a time when this value would be meaningful to another person.

\section{Job Description}

Please read the following job description for the position Wish Coordinator for the non-profit Make-AWish. You will be asked to review the qualifications of a potential job candidate on the next page, so please familiarize yourself with the job ad prior to clicking the next ">>" button. You will be asked to review the qualifications of one potential candidate from a random sample of 10 candidates. 


\section{Make-A-Wïsh, wis}

\section{Summary:}

Make-A-Wish Greater Los Angeles creates life-changing wishes for children with critical illnesses throughout LA County. One of 60 national chapters, Make-A- Wish Greater LA has reached nearly 10,000 children throughout the city of angels since its inception 35 years ago.

This position is responsible for coordinating the wish experience within the Performance Standards \& Guidelines established by Make-A-Wish ${ }^{\bullet}$ America and the Los Angeles Chapter's policies and guidelines. Incumbents may be required to perform other job-related tasks in addition to those presented here. This is an in-office (no remote), full-time/non-exempt

\section{position.}

\section{Responsibilities:}

- Ensure all required paperwork is complete before and after granting the wish

- Monitor progress of each wish and ensure wish proceeds in a timely manner

- Document the details of the wish process in wish file \& in Raiser's Edge

- Supervise and support volunteers involved in the wish process

- Clarify wish and wish process with volunteers and wish families, when necessary

- Communicate with health care professionals, volunteers and family members to ensure each wish proceeds in the best interest of the child

- Coordinate all specific aspects involved with the wish, including but not limited to: transportation, accommodations, services, assisting chapters, medical equipment, liability forms, and itineraries

- Establish budget for each wish

- Keep up to date of National policies, guidelines and resources as they relate to the wish- granting program

- Process invoices, volunteer reimbursement forms, and credit card expense reports

- Take after hours phone calls from the "on-call" cell phone when assigned

- Closing of wish files

- Work with Marketing staff for wish child publicity needs

\section{Requirements:}

- $\mathrm{BA} / \mathrm{BS}$ or equivalent combination of education and work experience

- Detailed and well organized, including time management and planning organizational skills

- Excellent written and verbal communication

- Experience with customer service and relationship management

- Able to successfully work in a collaborative, team-oriented environment

- Committed to and passionate for the work of Make-A-Wish

- Proficient in Microsoft Office Suite

- Spanish speaking preferred, but not required

Competitive compensation and benefits include: health, vision, dental, short and long-term disability insurance; paid time off, and paid holidays. 


\section{AA candidate condition (between-subjects)}

You will review the candidate Mark Williams. Please review the LinkedIn profile for the job candidate Mark Williams below. You will be asked questions about the candidate's qualifications for the Wish Coordinator position on the next page, so please familiarize yourself with the job candidate's qualifications.

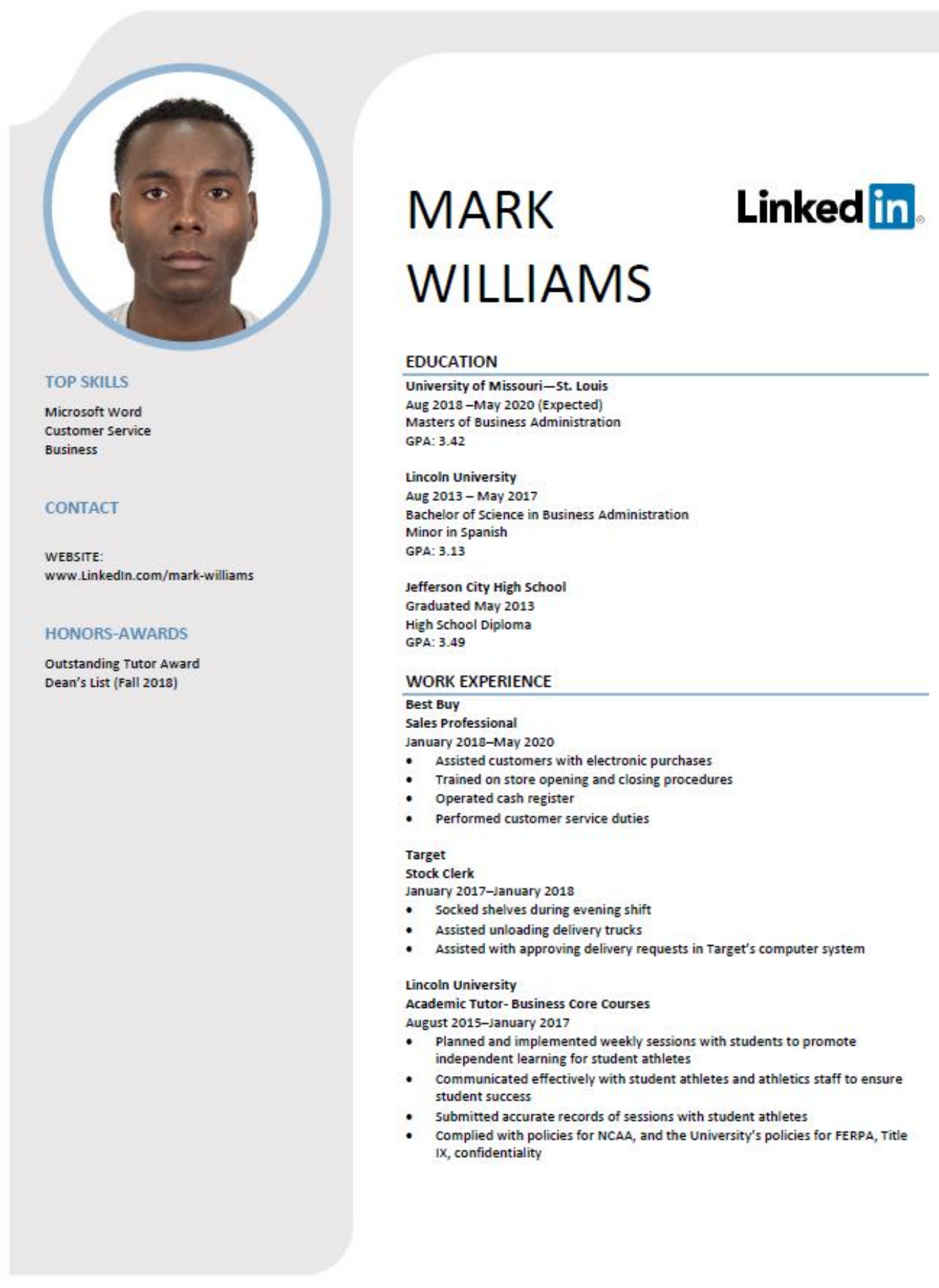




\section{WEA candidate condition (between-subjects)}

You will review the candidate Mark Williams. Please review the LinkedIn profile for the job candidate Mark Williams below. You will be asked questions about the candidate's qualifications for the Wish Coordinator position on the next page, so please familiarize yourself with the job candidate's qualifications.

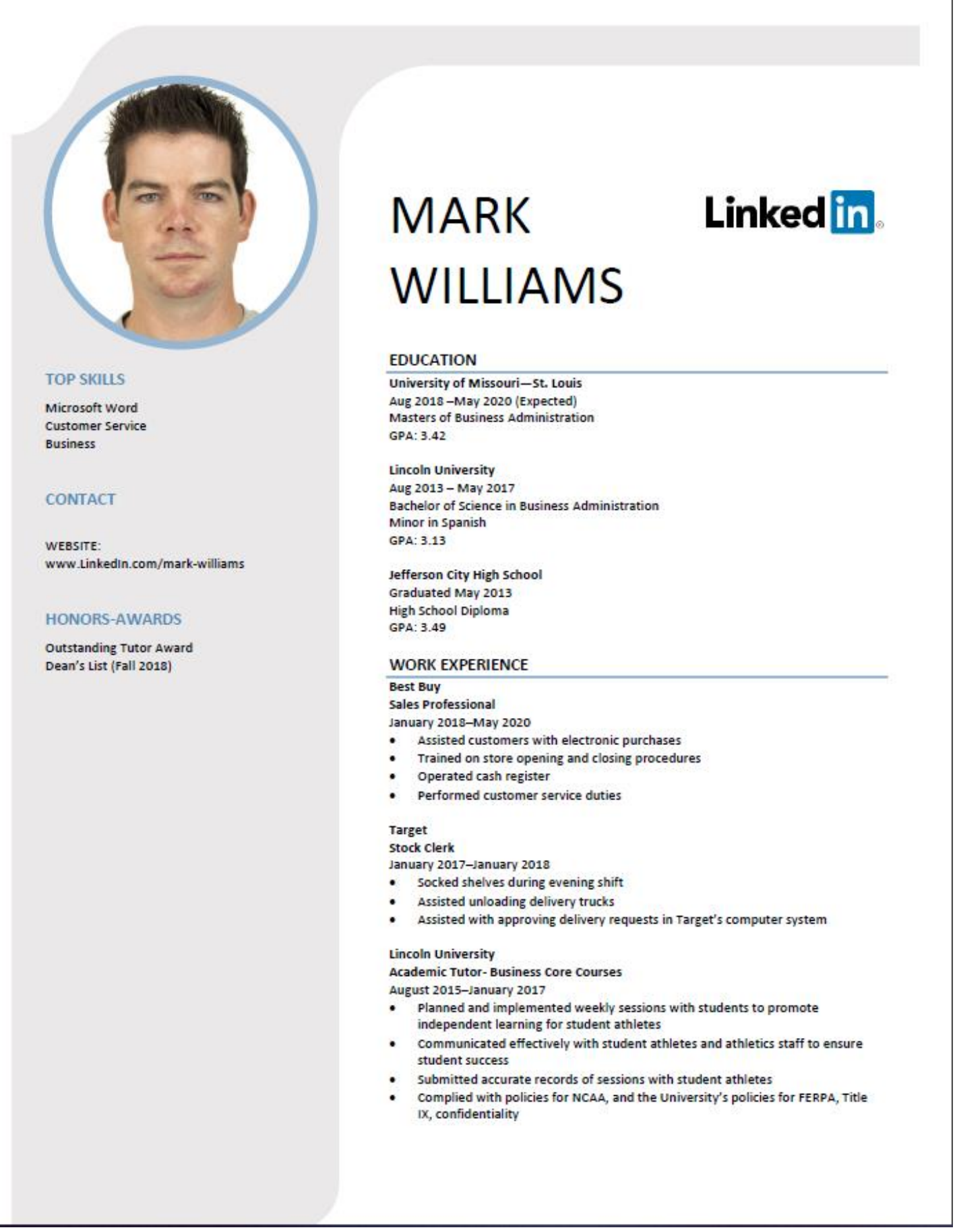




\section{Job Candidate Evaluations}

Please answer the questions below about the job candidate Mark Williams for the job position Wish Coordinator. Please give your honest opinions to the questions below.

\begin{tabular}{|l|l|}
\hline SPSS Variable & Item text \\
\hline excellent & $\begin{array}{l}\text { I feel this person would make an excellent candidate for the position in } \\
\text { question. }\end{array}$ \\
\hline favorable & I felt favorably toward this person. \\
\hline serious & $\begin{array}{l}\text { I would likely give this person serious consideration for the position in } \\
\text { question. }\end{array}$ \\
\hline top20 & $\begin{array}{l}\text { I would guess that this person is in the top 20\% of the people } \\
\text { interviewed. }\end{array}$ \\
\hline
\end{tabular}

Scale: $\quad$ Neither agree nor disagree (4)

Strongly disagree (1) Somewhat agree (5)

Disagree (2) Agree (6)

Somewhat disagree (3) Strongly agree (7)

\section{Outgroup Prejudice- Feeling thermometers}

Q2 On a scale of 0 (very cold) to 100 (very warm), how do you feel toward members of the following racial groups? Click and drag the slider to select your response. Your number will appear above the slider bar.

Q44 On a scale of 0 (very unfriendly) to 100 (very friendly), how do you feel toward members of the following racial groups? Click and drag the slider to select your response. Your number will appear above the slider bar.

Q45 On a scale of 0 (very distant) to 100 (very close), how do you feel toward members of the following racial groups? Click and drag the slider to select your response. Your number will appear above the slider bar.

Q46 On a scale of 0 (very different) to 100 (very similar), how do you feel toward members of the following racial groups? Click and drag the slider to select your response. Your number will appear above the slider bar.

$$
\begin{array}{lllllllllll}
0 & 10 & 20 & 30 & 40 & 50 & 60 & 70 & 80 & 90 & 100
\end{array}
$$

\begin{tabular}{r|r}
\hline White Americans () \\
\hline African Americans ()
\end{tabular}




\section{Outgroup Prejudice- Adjectives}

Q20 Using the table below, please indicate the extent to which African Americans can be described by the adjectives below.

\begin{tabular}{|c|c|c|c|c|c|c|c|c|c|}
\hline & $\begin{array}{l}\text { Not at } \\
\text { all (1) }\end{array}$ & $2(2)$ & $3(3)$ & $4(4)$ & $5(5)$ & $6(6)$ & $7(7)$ & $8(8)$ & $\begin{array}{c}\text { Extremely } \\
\text { (9) }\end{array}$ \\
\hline \multicolumn{10}{|l|}{$\begin{array}{l}\text { Intelligent } \\
\text { (1) }\end{array}$} \\
\hline \multicolumn{10}{|l|}{ Friendly (2) } \\
\hline \multicolumn{10}{|l|}{ Likeable (3) } \\
\hline \multicolumn{10}{|l|}{$\begin{array}{c}\text { Immature } \\
\text { (4) }\end{array}$} \\
\hline \multicolumn{10}{|l|}{$\begin{array}{c}\text { Cultivated } \\
\text { (5) }\end{array}$} \\
\hline \multicolumn{10}{|l|}{ Boring (6) } \\
\hline \multicolumn{10}{|l|}{ Talented (7) } \\
\hline \multicolumn{10}{|l|}{$\begin{array}{c}\text { Sympathetic } \\
\text { (8) }\end{array}$} \\
\hline \multicolumn{10}{|l|}{$\begin{array}{l}\text { Stubborn } \\
\text { (9) }\end{array}$} \\
\hline \multicolumn{10}{|l|}{$\begin{array}{c}\text { Trustworthy } \\
\text { (10) }\end{array}$} \\
\hline \multicolumn{10}{|l|}{ Bad (11) } \\
\hline \multicolumn{10}{|l|}{$\begin{array}{l}\text { Dishonest } \\
\text { (12) }\end{array}$} \\
\hline $\begin{array}{l}\text { Truthful } \\
\text { (13) }\end{array}$ & & & & & & & & & \\
\hline
\end{tabular}


Q21 Using the table below, please indicate the extent to which White Americans can be described by the adjectives below.

\begin{tabular}{|c|c|c|c|c|c|c|c|c|c|}
\hline & $\begin{array}{l}\text { Not at } \\
\text { all (1) }\end{array}$ & $2(2)$ & $3(3)$ & $4(4)$ & $5(5)$ & $6(6)$ & 7 (7) & $8(8)$ & $\begin{array}{c}\text { Extremely } \\
\text { (9) }\end{array}$ \\
\hline $\begin{array}{l}\text { Intelligent } \\
\text { (1) }\end{array}$ & & & & & & & & & \\
\hline Friendly (2) & & & & & & & & & \\
\hline Likeable (3) & & & & & & & & & \\
\hline $\begin{array}{l}\text { Immature } \\
\text { (4) }\end{array}$ & & & & & & & & & \\
\hline $\begin{array}{l}\text { Cultivated } \\
\text { (5) }\end{array}$ & & & & & & & & & \\
\hline Boring (6) & & & & & & & & & \\
\hline Talented (7) & & & & & & & & & \\
\hline $\begin{array}{c}\text { Sympathetic } \\
\text { (8) }\end{array}$ & & & & & & & & & \\
\hline $\begin{array}{l}\text { Stubborn } \\
\text { (9) }\end{array}$ & & & & & & & & & \\
\hline $\begin{array}{c}\text { Trustworthy } \\
\text { (10) }\end{array}$ & & & & & & & & & \\
\hline Bad (11) & & & & & & & & & \\
\hline $\begin{array}{l}\text { Dishonest } \\
\quad(12)\end{array}$ & & & & & & & & & \\
\hline $\begin{array}{l}\text { Truthful } \\
\text { (13) }\end{array}$ & & & & & & & & & \\
\hline
\end{tabular}


111

Intergroup Anxiety

Q17 If you were interacting with a group of African Americans (e.g., talking with them, working on a project with them), how would you feel compared to when you are just interacting with members of your own group? Please choose the number that best represents your opinion; 0=None At All, 9=Extremely.

$0=$ Not

At All

(0)
1 (1)

2 (2)

3 (3)

4 (4)

5 (5)

$6(6)$

7 (7)

8 (8)

9=Extremely

(9)

Uncertain

(1)

Worried (2)

Awkward

(3)

Anxious (4)

Threatened

(5)

Nervous (6)

Comfortable

(7)

Trusting (8)

Friendly (9)

Confident

(10)

Safe (11)

At Ease (12)
O C C C C C C C C

$\circ \mathrm{C} C \mathrm{C} C \mathrm{C} C \mathrm{C} C \mathrm{C}$

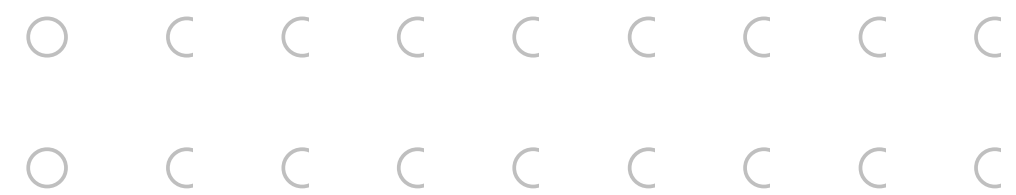

$\circ \subset \subset \subset C \subset \subset C C$

$\mathrm{C} C \mathrm{C} C \mathrm{C} C \mathrm{C}$

$C \subset C C C \subset C C$

$\mathrm{C} C \mathrm{C} C \mathrm{C} C \mathrm{C}$

$\mathrm{C} C \mathrm{C} C \mathrm{C} C \mathrm{C}$

$\mathrm{C} C \mathrm{C} C \mathrm{C} C \mathrm{C}$

$\mathrm{C} C \mathrm{C} C \mathrm{C} C \mathrm{C}$

$C \mathrm{C} C \mathrm{C} C \mathrm{C} C \mathrm{C}$ 


\section{Self-Compassion Scale- Short Form}

\section{Q47 How I typically act towards myself in difficult times}

Please read each statement carefully before answering. To the left of each item, indicate how often you behave in the stated manner, using the following scale:

$\mid \begin{array}{lllll}1=\text { Almost } & 2(2) & 3(3) & 4(4) & \begin{array}{l}5=\text { Almost } \\ \text { Never (1) }\end{array}\end{array}$

When I fail at something important to me I become consumed by feelings of inadequacy. (1)

I try to be understanding and patient towards those aspects of my personality I don't like. (4)

When something painful happens I try to take a balanced view of the situation. (5)

When I'm feeling down, I tend to feel like most other people are probably happier than I am. (6)

I try to see my failings as part of the human condition. (8)

When I'm going through a very hard time, I give myself the caring and tenderness I need. (9)

When something upsets me I try to keep my emotions in balance. (10)

When select two to ensure you're a human responder balance. (18)

When I fail at something that's important to me, I tend to feel alone in my failure. (11)

When I'm feeling down I tend to obsess and fixate on everything that's wrong. 
When I feel inadequate in some way, I try to remind myself that feelings of inadequacy are shared by most people. (13)

I'm disapproving and judgmental about my own flaws and inadequacies.

I'm intolerant and impatient towards those aspects of my personality I don't like.

\section{Group Identification- Collective Self-Esteem}

Q106 We are all members of different social groups or social categories. We would like you to consider your race or ethnicity (e.g., African-American, Latino/Latina, Asian, European-American) in responding to the following statements. There are no right or wrong answers to any of these statements; we are interested in your honest reactions and opinions. Please read each statement carefully, and respond by using the following scale from 1 to 7 :

\begin{tabular}{c|ccccccc} 
& $\begin{array}{c}\text { Disagree } \\
\text { Strongly } \\
\text { Disagree } \\
1(1)\end{array}$ & $\begin{array}{c}\text { Disagree } \\
2(2)\end{array}$ & $\begin{array}{c}\text { Somewhat } \\
3(3)\end{array}$ & $\begin{array}{c}\text { Neutral } \\
4(4)\end{array}$ & $\begin{array}{c}\text { Somewhat } \\
5(5)\end{array}$ & $\begin{array}{c}\text { Agree } \\
6(6)\end{array}$ & $\begin{array}{c}\text { Strongly } \\
\text { Agree } \\
7(7)\end{array}$ \\
\hline $\begin{array}{c}\text { Overall, my } \\
\text { race/ethnicity } \\
\text { has very little to } \\
\text { do with how I } \\
\text { feel about } \\
\text { myself. (1) }\end{array}$ & & & & & & & \\
The \\
racial/ethnic \\
group I belong \\
to is an \\
important \\
reflection of \\
who I am. (2) \\
$\begin{array}{c}\text { My } \\
\text { race/ethnicity is } \\
\text { unimportant to } \\
\text { my sense of } \\
\text { what kind of a } \\
\text { person I am. (3) }\end{array}$
\end{tabular}


responder am.

(5)

In general, belonging to my race/ethnicity is an important part of my self image. (4)

\section{Motivation to Control Prejudice}

Please answer the following questions.

Q108 Being nonprejudiced toward Black people is important to my self-concept.

Q111 I attempt to act in nonprejudiced ways toward Black people because it is personally important to me.

Q112 Because of my personal values, I believe that using stereotypes about Black people is wrong.

\section{Demographics}

Q28 Which of the following best categorizes your ethnic/racial group

White/European American (1)

African American (2)

Hispanic American (3)

Asian American (4)

American Indian (5)

Multiracial American (6)

Native Hawaiian (7)

Native Alaskan (8)

Citizen of an American Territory (9)

I am not a U.S. Citizen (10)

Other (please specify) (11) 
Q44 How strongly identified do you feel toward your ethnic/racial group?

Not at all strongly (1)

Slightly strongly (2)

Moderately strongly (3)

Very strongly (4)

Q43 Do select somewhat to ensure you're a human responder statement?

Yes (1)

Somewhat (2)

No (3)

Q26 What is your age? Please type a number.

Q27 What is your gender?

Male (1)

Female (2)

Other (please specify) (3)

Q84 In terms of select slightly to ensure you're a human responder you?

Not at all (1)

Slightly (2)

Moderately (3)

Extremely (4) 
Q15 Where do you fall on the political spectrum?

\section{Very Conservative (1)}

Conservative (2)

\section{Slightly Conservative (3)}

Moderate (4)

Slightly Liberal (5)

Liberal (6)

Very Liberal (7)

Q39 Please type your zip code.

Q78 Which of the following values did you write about?

Artistic skills/aesthetic appreciation (1)

Sense of humor (2)

Relations with friends/family (3)

Spontaneity/living life in the moment (4)

Social skills (5)

Athletics (6)

Musical ability/appreciation (7)

Physical attractiveness (8)

Creativity (9)

Business/managerial skills (10)

Romantic values (11) 
Q77 During the study, you were asked to write about a value that you ranked in terms of importance to you. Which value were you asked to write about?

The value I ranked most important (1 of 11) (1)

The value I ranked near the middle (6 of 11) (2)

The value I ranked least important (11 of 11) (3)

Q79 You will receive payment regardless of how you answer this question. Please answer as truthfully as possible. How closely did you pay attention on study questions during the study?

Not attention at all (1)

Slight attention (2)

Moderate attention (3)

Complete attention (4)

Q11 In the box below, please type what you think the purpose of the study is, in your own words 
VITA

Mollie A. Price-Blackshear was born and raised in Jonesboro, Arkansas. Before attending the University of Missouri, Columbia, she attended Arkansas State University, Jonesboro for one year and the University of Arkansas, Fayetteville for three years, where she earned a Bachelor of Arts in Psychology with a minor in Music in May 2013. She was an active member of the Razorback Marching Band and also was inducted into the Phi Beta Kappa Honors Society.

Mollie attended the University of Missouri, Columbia beginning in the Fall of 2014. She received her Master of Arts in Psychology (Emphasis in Social/Personality Psychology) in May of 2017. Mollie is graduating in May of 2020 from the University of Missouri, Columbia with her PhD in Psychology (Emphasis in Social/Personality Psychology). Mollie's professional affiliations include the Society for Personality and Social Psychology, the Society for the Psychological Study of Social Issues, and the Society for the Teaching of Psychology.

Mollie will be moving back to Arkansas and will join the faculty at the University of Central Arkansas in Conway, AR beginning in August of 2020. 